\title{
Identification and Visualization of the Intellectual Structure in Graphene Research
}

\begin{abstract}
Benjamín Vargas-Quesada, ${ }^{1,2 *}$, Zaida Chinchilla-Rodríguez ${ }^{2,3}$ and Noel Rodriguez ${ }^{4}$
'Departmento de Información y Comunicación, Universidad de Granada, Granada, Spain, ${ }^{2}$ SCImago Research Group, Granada, Spain, ${ }^{3}$ Instituto de Políticas y Bienes Públicos (IPP), Consejo Superior de Investigaciones Científicas (CSIC). Madrid, Spain, ${ }^{4}$ Departamento de Electrónica y Tecnología de Computadores, Universidad de Granada, Granada, Spain
\end{abstract}

Since the discovery of the promising properties of graphene, research in the field has attracted numerous grants and sponsors, leading to an exponential rise in the number of papers and applications. This article presents a global map of graphene research and its intellectual structure, drawn using the terms of more than 50,000 documents extracted from Scopus database, years 1998-2015. The unit of analysis consisted of descriptors (including Author Keywords and Indexed Keywords), with the co-occurrence of descriptor as the unit of measure, using fractional counting. The main research lines identified are: Fundamental Research, Functionalization and Biomedical Applications, Technology and Devices, Materials Science, Energy Storage, Optics and Chemical Properties and Sensors. Using overlay maps, we depict the graphene research efforts of the United States, the European Union (Europe-28), and China, and project their evolution through longitudinal maps to facilitate comparison. The United States was initially at the head of
OPEN ACCESS

Edited by: Chaomei Chen, Drexel University, United States

Reviewed by:

M. J. Cobo,

University of Cádiz, Spain Erjia Yan, Drexel University, United States

*Correspondence: Benjamin Vargas-Quesada benjamin@ugr.es

Received: 25 July 2017 Accepted: 25 September 2017 Published: 25 October 2017

Citation: Vargas-Quesada B, Chinchilla-Rodríguez $Z$ and Rodriguez N (2017) Identification and Visualization of the Intellectual Structure in Graphene Research.

Front. Res. Metr. Anal. 2:7. doi: 10.3389/frma.2017.00007 world output in graphene research, but was surpassed by China in 2011 and by Europe in 2014, as a result of their respective scientific policies and financial support. The output of China has since been so intense that it can be said to mark graphene research trends. We believe this information may be valuable for the core community involved in this scientific field, as it offers a large-scale analysis showing how research has changed over time. It is therefore also helpful for policy makers and research planners. The resulting maps are a useful and attractive tool for the graphene research community, as they reveal the main lines of exploration at a glance. The methodology described here could be re-created in any other field of science to uncover and display its intellectual structure and evolution over time.

Keywords: graphene, information visualization, bibliometric analysis, co-words, intellectual structure, research lines, evolution

\section{INTRODUCTION}

New carbon nanostructures-fullerenes, nanotubes and, above all, graphene-have aroused great interest in recent years, making the field of graphene research undergo phenomenal growth that comes to light in publications.

Graphene is a one-atom-thick layer of carbon with exceptional physical and chemical properties and a potential for revolutionary applications in a wide variety of fields: strong lightweight materials, 
new-generation electronic units, specialized coatings, novel biomaterials and sensors, and innovative medical applications (Novoselov et al., 2012). Back in 1947 (Wallace, 1947), planar graphene was theoretically presumed not to exist in a free, stable state (Odegard et al., 2002). Within the framework of carbonbased materials, however, this 2-D material suddenly aroused the attention of scientists (Lv et al., 2011). With the experimental discovery of graphene by Novoselov et al. (2004), a rapidly growing stream of scientific literature became fertile land for bibliometric studies: Barth and Marx (2008), Wan and Pan (2010), Shapira et al. (2010), Lv et al. (2011), Munoz-Sandoval (2014), Small et al. (2014), Terekhov (2015), Klincewicz (2016), and Shapira et al. (2016).

As they say, a picture is worth a thousand words, and the notion behind information visualization is to create a mental picture of that which is invisible to our eyes. This idea arises from the conviction that an image facilitates comprehension, and invites one toward analysis better than text, numbers, or a combination thereof. Information visualization emerged at the beginning of this century as a discipline of great interest at the crossroads of bibliometrics and scientometrics, providing multiple visual representations known as scientograms (Moya-Anegón et al., 2007a). These maps of science can facilitate understanding of a scientific domain by depicting the structure of research output. At large, scientograms show relationships that occur between disciplines; and they may be used more specifically as an index to comprehend to what extent certain research lines or fields are connected with others (Vargas-Quesada and Moya-Anegón, 2007). They enable one to explore the sequential evolution of research, identify research fronts, detect emerging or decadent topics, and locate areas of interdisciplinary efforts (Gómez-Núñez et al., 2016).

Still, researchers persistently search for other underlying mechanisms that may explain certain changes and patterns within scientific networks (Chen, 2004). Bibliometric mapping tools and scientometric analyses have become increasingly sophisticated in order to reach more ambitious goals. In this work, we use automatic bibliometric mapping tools to show the intellectual structure of a relatively novel field, graphene research, joining the current debate about distinct counting approaches (full/fractional), and tracing its evolution to date.

\section{RELATED WORKS}

Co-word analysis (Callon et al., 1983, 1991; Leydesdorff, 1989) has been described-and later corroborated (Leydesdorff and Nerghes, 2017) - as the best approach to determine and set out the intellectual structure of a field at the level of research specialties (Braam et al., 1991a,b). It is furthermore able to bring to light new developments of a research line over time (Peters and van Raan, 1993a,b) and help policy makers understand the complex interrelations of science and their implications for effective research planning (He, 1999). Although co-word analysis has gradually been improved upon, while not all of its limitations have been overcome (Wang et al., 2012), this type of analysis can reveal the intellectual underpinnings of a wide variety of domains: chemistry (Callon et al., 1991), data retrieval (Ding et al., 2001), the fuzzy logic field (López-Herrera et al., 2010), women and health (Zulueta et al., 2011), keyword analysis (Cantos-Mateos et al., 2012), human intelligence networks (Wang et al., 2012), and stem cells (Cantos-Mateos et al., 2014). A recent study applied it to study the intellectual structure of nanotechnology and its evolution (Muñoz-Écija et al., 2017).

Information visualization has a very active role in the distribution and depiction of the intellectual structures related with scientific research lines (Chen et al., 2001). The use of scientograms to look onto/into science is not entirely new, offering a new standpoint to reveal the scientific frontiers and dynamic intellectual structure of a research line (Alcaide-Muñoz et al., in press). The pioneer efforts in this terrain go back to the 1960s, in fact. Science maps have been used to navigate around scholarly literature and the depiction of its internal relations (Garfield, 1986), to represent the spatial distribution of research areas and their relations (Small and Garfield, 1985) and to analyze and visualize the social or intellectual spry of scientific research fronts (Braam et al., 1991a,b; Noyons et al., 1999; Börner et al., 2003).

At the end of the 20th century, the lower price of computer equipment, along with an increased capacity of processing and storage components, not to mention big data and new algorithms, set the stage for a grand era in the first decade of this millennium, with the appearance of a wide variety of free software for science mapping analysis (Cobo et al., 2011a). Among many other achievements, science mapping become the keystone of visualizing and analyzing computer graphics (Chen et al., 2001), using ISI categories to represent science (Moya-Anegón et al., 2004), mapping the backbone of science (Boyack et al., 2005), evaluating large maps of disciplines (Klavans and Boyack, 2006), visualizing the citation impact of scientific journals (Leydesdorff, 2007a), mapping interdisciplinarity (Leydesdorff, 2007b), viewing the marrow of science (Moya-Anegón et al., 2007b), creating dynamic animations of journal maps (Leydesdorff and Schank, 2008), mapping the structure and evolution of chemistry research (Boyack et al., 2009), proposing a consensus map of science (Klavans and Boyack, 2009), creating a journal map using Scopus data (Leydesdorff et al., 2010), mapping the geography of science (Leydesdorff and Persson, 2010), clustering over two million biomedical publications (Boyack et al., 2011), creating more accurate document-level maps of research fields (Klavans and Boyack, 2011), detecting and visualizing the evolution of the fuzzy sets theory field (Cobo et al., 2011b), proposing a new global science map (Leydesdorff et al., 2013a,b; Boyack and Klavans, 2014), analyzing the investigation in integrative and complementary medicine (Moral-Muñoz et al., 2014), analyzing intelligent transportation systems (Cobo et al., 2014), showing the evolution of bases knowledge systems (Cobo et al., 2015), showing the scientific evolution of social work (Martínez et al., 2015), outlining animal science research (Rodriguez-Ledesma et al., 2015), studying the conceptual evolution of marketing research (Murgado-Armenteros et al., 2015) identifying and depicting the intellectual structure and research fronts in nanoscience and nanotechnology in the world (Muñoz-Écija et al., 2017), and exploring the scientific evolution of e-Government (Alcaide-Muñoz et al., in press), among other brave new initiatives. 
The proposal by Leydesdorff and Rafols (2009) of creating overlay maps can be seen as a powerful contribution integrating visualization, intellectual structure, evolution, and benchmarking, for any kind of scientific domain. Indeed, overlay maps soon proved useful for research policy and library management (Rafols et al., 2010), to build interactive overlays (Leydesdorff and Rafols, 2012), to map patent data (Leydesdorff and Bornman, 2012), to gauge interdisciplinarity (Leydesdorff et al., 2013a,b), and to appraise strategic intelligence in emerging technologies (Rotolo et al., 2017).

In the wake of the above study embracing N\&N, we chose to focus our attention on the application of information visualization techniques to the monolayer of $\mathrm{sp}^{2}$-bonded carbon atoms known as graphene, a topic attracting worldwide interest not only because of its unique 2-D structure, fascinating properties, and wide range of potential applications (Chen, 2013), but also due to its intriguing intellectual structure and evolution, now ripe for comparison.

\section{OBJECTIVES AND RESEARCH QUESTIONS}

This study is intended to serve as a focal point, with the main goal of testing a methodology that reveals at a glance the main research lines involving graphene, based on scientific information. The questions that became our guidelines for analysis were:

1. How vast and varied is graphene research output?

2. What is the intellectual structure of graphene research worldwide?

3. Can overlay maps be used to explore the evolution of graphene research?

4. Can the intellectual and geographical domains of graphene research be readily visualized, analyzed, and compared using overlay and density maps?

Perhaps the greatest novelty of this contribution lies in the use of overlay maps and fractional counting, which together allow us to map the disciplinary network structure of a research field in a way that helps identify terms which have a mediating effect, linking different developmental stages in diverse geographic domains. Our main aim is to offer the research community a methodology and tools serving to visualize the intellectual structure of any scientific domain by means of a base map, the main research lines, and the possibility of benchmarking these scientific domains with others, or show their evolution using overlay maps. These tools and this methodology can be extrapolated to any area, discipline, or research field. Given the acute and rising importance of graphene research, it appeared to be a topic of great interest to validate our approach.

\section{MATERIALS AND METHODS}

The data set was obtained on June 5, 2017, from Scopus database.

Traditionally, the most commonly used databases for bibliometric studies have been those of the Web of Science (WoS).
However, the appearance on the market in 2004 of the Scopus of Elsevier, also having a multidisciplinary scope and a greater coverage of journals from diverse geographic regions (MoyaAnegón et al., 2007a) made an alternative source of great value for studies of the scientific output of countries, institutions, and disciplines. Even with the unprecedented inclusion of journals in both databases as a part of expansion in their coverage (Leta, 2011; Collazo-Reyes, 2014), Scopus offers a stronger coverage of journals not exclusively written in English (22,800 as opposed to the 18,000 of WoS), which provides for a more representative geographical picture of Graphene research. Granted, WoS has strong coverage which goes back to 1990 (Chadegani et al., 2013), but this was not especially relevant for our objectives.

Moreover, bearing in mind the methodology behind this work, currently WoS is more time-consuming than Scopus due to the fact that it is no longer possible (since about a year ago) to do searches in WoS with the field Keyword (Author Keywords and Index Keywords), one of the premises emphasized here, as a necessity to properly delimit the object of study. At present and in order to execute a similar delimitation, ISIWoS "only" offers the option of doing searches with the field "Topic," which includes searching the fields: Title, Abstract, Author Keywords, and Index Keywords, yet with considerable documental noises in the results.

The search strategy used to retrieve all the documents published worldwide on graphene was very simple: [KEY ("single layer graphit*”) OR KEY (graphene)] AND [EXCLUDE (PUBYEAR, 2016) OR EXCLUDE (PUBYEAR, 2017)].

To validate the proposed methodology of overlay maps, it is necessary that the data used to generate the intellectual structure (basemap) be as comprehensive as possible (use of Scopus) and that they be complete so that the structure will remain invariable over time. This criterion allows for the map to be used as a reference or object of comparison in future work by other researchers, whether it be to analyze further geographic domains not addressed in this study, or to analyze the implications of just how the input (or output) of journals in the Scopus database is effected and its updating policy in the representation of the different domains and research lines.

After downloading and analyzing the evolution over time of the number of documents (Figure 1), we observed a decreased growth rate in the two final years of study, as seen in the table below. Deducing that the data were incomplete, we decided to exclude the years 2016 and 2017 from this study. This table, along with the data for the top 20 graphene-producing countries, can be found below.

Keywords have as their main objective to provide rapid access to scientific works (Soos et al., 2013). Author Keywords provide the "author aboutness," that is, contents expressed through terms in natural language, while Indexed Keywords give the interpretation of contents (Stock and Stock, 2013). The usefulness of this approach was confirmed by Zhang et al. (2016), who hold that Author Keywords are highly effective in terms of bibliometric analysis when investigating the knowledge structure of scientific fields, and Indexed Keywords are very comprehensive for representing an article's content. Other authors argue that keyword-based analyses might be biased, suggesting some scientists could use certain keywords to seek increased visibility 


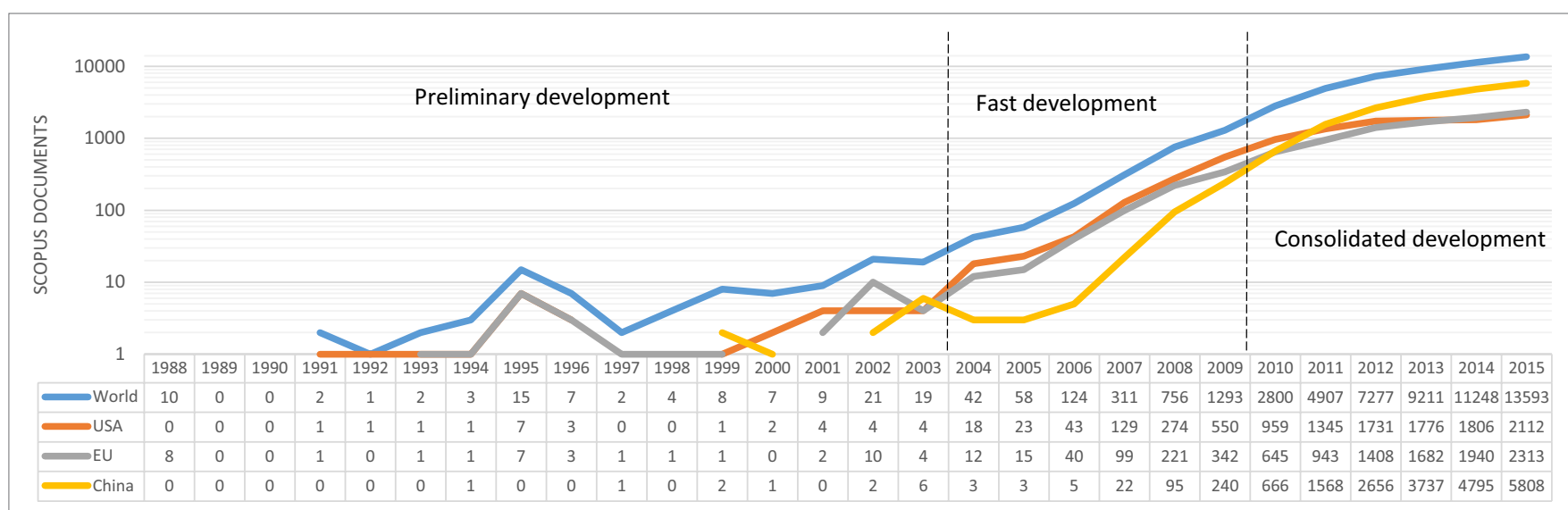

FIGURE 1 | Count and evolution of documents on graphene research in Scopus database.

(Bonaccorsi, 2008). In our view, the combination of Author Keywords and Indexed Keywords, eliminating duplications, is the optimal approach, combining the robustness of both realms.

The expression "single layer graphite" has come to largely replace the word graphene (Lv et al., 2011), for which reason we decided to include it in our search equation. It was right-truncated to include the singular and the plural. In our case, this inclusion led us to obtain just one more document, however. It should be stressed that such a truncation can be very problematic, as graphen* leads to the retrieval of 386 documents containing the German root "graphen": for instance "graphs" in English, which does not pertain to the context of study. Also excluded were the data from 2016 to 2017, as we wished to be certain that the final year of analysis, 2015, was fully registered in the database. No restriction has been made based on the document type, language of publication, country, or other such element. The search equation for the rest of the geographic domains of study was the same as applied for the worldwide level, only delimited by the geographic affiliation of the authors. Hence, for the United States [KEY ("single layer graphit*") OR KEY (graphene)] AND [EXCLUDE (PUBYEAR, 2016) OR EXCLUDE (PUBYEAR, 2017)] AND [LIMIT-TO(AFFILCOUNTRY, “UnitedStates")].ForChina:[KEY ("single layer graphit*") OR KEY (graphene)] AND [EXCLUDE (PUBYEAR, 2016) OR EXCLUDE (PUBYEAR, 2017)] AND [LIMIT-TO (AFFILCOUNTRY, “China”)]. Finally, the European Union (EU) was delimited by country, for each of the 28 member states: [KEY ("single layer graphit*") OR KEY (graphene)] AND [AFFILCOUNTRY (austria) OR AFFILCOUNTRY (belgium) OR AFFILCOUNTRY (bulgaria) OR AFFILCOUNTRY (croatia) OR AFFILCOUNTRY (cyprus) OR AFFILCOUNTRY (czech AND republic) OR AFFILCOUNTRY (denmark) OR AFFILCOUNTRY (estonia) OR AFFILCOUNTRY (finland) OR AFFILCOUNTRY (france) OR AFFILCOUNTRY (germany) OR AFFILCOUNTRY (greece) OR AFFILCOUNTRY (hungary) OR AFFILCOUNTRY (ireland) OR AFFILCOUNTRY (italy) OR AFFILCOUNTRY (latvia) OR AFFILCOUNTRY (lithuania) OR AFFILCOUNTRY (luxembourg) OR AFFILCOUNTRY (malta) OR AFFILCOUNTRY (netherlands) OR AFFILCOUNTRY (poland) OR AFFILCOUNTRY (portugal) OR AFFILCOUNTRY
(romania)ORAFFILCOUNTRY (slovakia)ORAFFILCOUNTRY (slovenia) OR AFFILCOUNTRY (spain) OR AFFILCOUNTRY (sweden) OR AFFILCOUNTRY (united AND kingdom)] AND [EXCLUDE (PUBYEAR, 2016) OR EXCLUDE (PUBYEAR, 2017)].

Among the great variety of freely available computer programs to perform a science mapping analysis, we looked into CiteSpace (Chen, 2004, 2006), SciMAT (Cobo et al., 2012), and VOSviewer (Van Eck and Waltman, 2010). The pros of the first two are the facility of making evolutive or longitudinal studies, the support of smart techniques to make it easier to analyze a research line by automatically categorizing its research outputs/results into different subjects, and to highlight the clusters with high impact through citation counting. One particular advantage lies in the scientific support tools to uncover and label the conceptual structure of a research line of interest. The pros of the third option would be: the quality of the displays, the ease of working directly with Scopus data (one of our research aims) without any loss of information, together with the possibility of generating the overlay maps manually (another research objective), and the fact that they could be processed and depicted easily with the software. The proximity with our research objectives led us to select the latter software alternative. It is a software tool for building and depicting networks based on bibliometric data. It features a text mining instrument that can be used to depict co-occurrence networks of terms extracted from any part of scientific literature. With our focus on the knowledge structure and main lines of graphene research, we selected Author Keywords in conjunction with Indexed Keywords as the unit of analysis; their co-occurrence was, as we mentioned before, the unit of measurement. The most popular methodologies for estimating co-occurrence are the full counting (whole counting for others) and the fractional counting (Aksnes et al., 2012). In the case of the full counting method, for instance, when one keyword co-occurs with another five within a single document, it would be assigned a full weight of one. Under the fractional counting method, the co-occurrence is assigned to each keyword with a fractional weight of $1 / 6$. Thus, fractional counting in the latter case divides the credit among co-authors (countries, institutions, etc.), whereas fractional counting at the 
network level can normalize the relative weights of links and thereby clarify the structures in the network.

One of the co-authors of this study is a graphene technologist, who helped us confirm the relevance of terms used. After analyzing and carefully studying the keywords in each cluster, detected by full counting and by fractional counting, we concluded that fractional counting gave more realistic results. That is, it better reflected what is actually the subject of study, not just the field covered by the Journal at hand, as would be the case with full counting. A similar conclusion was drawn by Perianes-Rodriguez et al. (2016) regarding other units of analysis.

For the generation of the basemap, where the intellectual structure of the world of graphene would be depicted, we used a threshold of co-occurrence of over three. According to previous observations, a lower threshold produces distortion and informational noise, while a higher threshold gives rise to a loss of information. We think it is best not alter the idea of keywords as settled and picked by the authors or the automatic indexing system. Yet as it is possible for two different keywords to be used to define the same concept, their normalization is absolutely necessary. Accordingly, duplicates are eliminated, plural and singular forms are standardized to the form showing a higher figure for occurrence in the database, empty words or words out of context are deleted, abbreviations or acronyms are replaced by the complete term whenever possible, followed by the acronym or abbreviation between parenthesis, etc. In normalizing the terms, an ad hoc thesaurus containing 25.603 equivalences was created, which is available at: http://www.ugr.es/local/benjamin/frontiers/ thesauro.txt.

To produce the scientograms, parameters such as layout attraction, layout repulsion, and clustering resolution were set to the default values. Only the minimum cluster size parameter was changed, here to 100 . The overlay maps were built following the same procedure, although-as their name suggests-they were superimposed upon the basemap, and the words that did not coincide were eliminated. In this way, the overlay map of every domain or period provides its knowledge structure in the form of its total keywords; the 22,000 plus keywords in the basemap function, therefore, serve as a filter. Each circle represents a keyword, and its size is proportionate to the number of times that it occurs in the documents represented. The distance between two particular circles would approximately indicate the level of cooccurrence between two terms-the closer they are, the tighter or stronger their conceptual relationship, etc. and vice versa. The colors represent the clusters that were identified automatically, by means of clustering techniques, based on the level of proximity among terms (Waltman et al., 2010).

For complementary analyses, we also generated density maps, as they prove very useful for more detailed or evolutive studies of the intellectual structure put forth. In these maps, keywords are indicated by their label. Each point in a scientogram has a color that depends on the density of keywords at that point. By default, the color is somewhere in between red and blue. The greater the number of keywords in the neighborhood of a point, and the higher the weights of the neighboring items, the more reddish the color of the point. Conversely, a smaller number of items around the point, with lower weights of the neighboring items, would mean that the color of the point is closer to blue (Van Eck and Waltman, 2016). Similarly, the intensity level in terms of density, from less to more, is depicted by: blue, green, yellow, and red.

All the maps produced in the framework of this study can be visualized in high resolution by clicking on the link indicated in each case. They may also be viewed using the online version of VOSviewer. To this end, we give the link that allows the reader to see the maps as well as the networks of each domain. Please note that for very broad domains and periods, e.g., the whole world, a computer with more than $8 \mathrm{~GB}$ of RAM is needed. If one has only 1 or $2 \mathrm{~GB}$, for instance, the second part of the link referring to the network may simply be omitted. In other words, http://www.vosviewer.com/vosviewer.php? map=http://www. ugr.es/local/benjamin/frontiers/graphene-m.txt\&label_size_ variation $=0.3 \&$ zoom_level $=1 \&$ scale $=0.9$ will take us to the maps alone, without any problem owing to limited memory.

\section{RESULTS AND DISCUSSION}

The results are divided below into six sections, according to the proposed research questions.

\section{Graphene Research Output}

Table 1 shows both the evolution of the scholarly production by the top 20 countries publishing research on graphene of worldwide as found in the Scopus database. In light of the results in this table, the goals of this paper as well as the recent programs and funding implemented by the European Commission to support graphene research efforts (Graphene Flagship, 2013), we believe that it may be of great interest both to researchers and decision-makers alike to put together all European countries so as to be able to compare the three world regions of highest production - the United States, the EU, and China, leaving out of the comparison the scholarly production by other countries worldwide for future research.

The output of graphene research grows substantially, but not steadily, from 1988 to 2015, as seen in Figure 1. There were 10 Scopus documents on graphene research in 1988, then zero in later years, with a peak of 13,593 in 2015. In view of this evolution, we divided output into three stages: Preliminary development (1988-2003), Fast development (2004-2009), and Consolidated development (2010-2015). That of Preliminary development is an unstable period. The highest output per year is 21 documents worldwide, and 10 in the case of the EU, both in the year 2002. The United States reached its peak of output in 1995 with seven documents. China published its very first document on graphene in 1994, and it was not until 1999 that it managed to publish more than one document per year.

Then the race began. In the period of Fast development, the United States (in 2004) and Europe and China (in 2006) hit new heights in scientific production. Europe and China apparently benefit from encouraging scientific policy that also affects graphene research. It shows exponential growth at the worldwide level from 2004 (Lv et al., 2011) to 2005 (Wan and Pan, 2010), demonstrating the great interest awakened among researchers working with this material. Most surprising is the trend seen for 
TABLE 1 | Evolvement of scholarly production on graphene by the top 20 countries worldwide.

\begin{tabular}{|c|c|c|c|c|c|c|c|c|c|c|c|c|c|c|c|c|c|c|}
\hline & 2000 & 2001 & 2002 & 2003 & 2004 & 2005 & 2006 & 2007 & 2008 & 2009 & 2010 & 2011 & 2012 & 2013 & 2014 & 2015 & 2016 & 2017 \\
\hline China & 1 & 0 & 2 & 6 & 3 & 3 & 5 & 22 & 95 & 649 & 666 & 1,568 & 2,655 & 3,749 & 4,799 & 5,386 & 6,108 & 5,024 \\
\hline Growth rate & & -100 & 0 & 200 & 50 & 0 & 66.67 & 340.00 & 331.82 & 583.16 & 2.62 & 135.44 & 69.32 & 41.21 & 28.01 & 12.23 & 13.41 & -17.75 \\
\hline United States & 2 & 4 & 4 & 4 & 18 & 23 & 41 & 123 & 273 & 465 & 940 & 1,346 & 1,730 & 1,789 & 1,808 & 2,145 & 1,904 & 1,374 \\
\hline Growth rate & & 100 & 0 & 0 & 350 & 27.78 & 78.26 & 200 & 121.95 & 70.33 & 102.15 & 43.19 & 28.53 & 3.41 & 1.06 & 18.64 & -11.24 & -27.84 \\
\hline South Korea & 0 & 0 & 0 & 0 & 2 & 2 & 1 & 7 & 31 & 60 & 209 & 485 & 677 & 889 & 1,087 & 1,282 & 1,117 & 806 \\
\hline Growth rate & & & & & & 0 & -50 & 600 & 342.86 & 93.55 & 248.33 & 132.06 & 39.59 & 31.31 & 22.27 & 17.94 & -12.87 & -27.84 \\
\hline India & 0 & 0 & 2 & 0 & 0 & 1 & 2 & 6 & 18 & 49 & 78 & 198 & 302 & 477 & 679 & 930 & 981 & 853 \\
\hline Growth rate & & & & & & & 100 & 200 & 200 & 172.22 & 59.18 & 153.85 & 52.53 & 57.95 & 42.35 & 36.97 & 5.48 & -13.05 \\
\hline Japan & 4 & 3 & 8 & 2 & 12 & 14 & 26 & 45 & 83 & 129 & 227 & 385 & 468 & 513 & 492 & 518 & 550 & 369 \\
\hline Growth rate & & -25 & 166.6 & -75 & 500 & 16.67 & 85.71 & 73.08 & 84.44 & 55.42 & 75.97 & 69.60 & 21.56 & 9.62 & -4.09 & 5.28 & 6.18 & -32.91 \\
\hline Germany & 0 & 0 & 3 & 1 & 2 & 3 & 11 & 27 & 64 & 98 & 169 & 259 & 320 & 427 & 440 & 495 & 449 & 303 \\
\hline Growth rate & & & & -66.67 & 100 & 50 & 266.67 & 145.45 & 137.04 & 53.13 & 72.45 & 53.25 & 23.55 & 33.44 & 3.04 & 12.50 & -9.29 & -32.52 \\
\hline Iran & & & & & 1 & 2 & 3 & 4 & 9 & 16 & 50 & 86 & 128 & 230 & 389 & 536 & 802 & 703 \\
\hline Growth rate & & & & & & & 50 & 33.33 & 125 & 77.78 & 212.50 & 72 & 48.84 & 79.69 & 69.13 & 37.79 & 49.63 & -12.34 \\
\hline United Kingdom & 0 & 0 & 4 & 0 & 1 & 4 & 7 & 21 & 52 & 70 & 120 & 206 & 277 & 323 & 392 & 506 & 510 & 363 \\
\hline Growth rate & & & & & & & 75 & 200 & 147.62 & 34.62 & 71.43 & 71.67 & 34.47 & 16.61 & 21.36 & 29.08 & 0.79 & -28.82 \\
\hline Singapore & & & & & 2 & 1 & 2 & 6 & 27 & 38 & 145 & 233 & 330 & 336 & 322 & 361 & 287 & 159 \\
\hline Growth rate & & & & & & & 100 & 200 & 350 & 40.74 & 281.58 & 60.69 & 41.63 & 1.82 & -4.17 & 12.11 & -20.50 & -44.60 \\
\hline Italy & & & 2 & 1 & & 2 & 3 & 10 & 20 & 45 & 91 & 123 & 191 & 227 & 298 & 377 & 390 & 285 \\
\hline Growth rate & & & & -50 & & & 50 & 233.33 & 100.00 & 125 & 102.22 & 35.16 & 55.28 & 18.85 & 31.28 & 26.51 & 3.45 & -26.92 \\
\hline Spain & & & 1 & & 2 & 3 & 6 & 11 & 30 & 46 & 73 & 129 & 208 & 221 & 253 & 325 & 351 & 263 \\
\hline Growth rate & & & & & & 50 & 100 & 83.33 & 172.73 & 53.33 & 58.70 & 76.71 & 61.24 & 6.25 & 14.48 & 28.46 & 8.00 & -25.07 \\
\hline Australia & & & & & & & 6 & 10 & 19 & 29 & 48 & 118 & 167 & 229 & 296 & 381 & 356 & 257 \\
\hline Growth rate & & & & & & & & 66.67 & 90.00 & 52.63 & 65.52 & 145.83 & 41.53 & 37.13 & 29.26 & 28.72 & -6.56 & -27.81 \\
\hline France & & 1 & 2 & 1 & 5 & 4 & 11 & 13 & 36 & 63 & 128 & 139 & 209 & 221 & 249 & 293 & 298 & 207 \\
\hline Growth rate & & & 100 & -50 & 400 & & 175 & 18.18 & 176.92 & 75.00 & 103.17 & 8.59 & 50.36 & 5.74 & 12.67 & 17.67 & 1.71 & -30.54 \\
\hline Taiwan & & & & & 1 & 2 & 1 & 5 & 16 & 27 & 62 & 122 & 214 & 247 & 331 & 316 & 306 & 225 \\
\hline Growth rate & & & & & & & -50 & 400 & 220 & 68.75 & 129.63 & 96.77 & 75.41 & 15.42 & 34.01 & -4.53 & -3.16 & -26.47 \\
\hline Russian Federation & 1 & & 2 & 1 & 1 & 3 & 3 & 9 & 15 & 29 & 63 & 106 & 154 & 187 & 221 & 269 & 301 & 203 \\
\hline Growth rate & & -100 & & -50 & 0 & & 0 & 200 & 66.67 & 93.33 & 117.24 & 68.25 & 45.28 & 21.43 & 18.18 & 21.72 & 11.90 & -32.56 \\
\hline Canada & & & & 2 & 1 & 1 & 4 & 12 & 21 & 28 & 41 & 86 & 118 & 143 & 189 & 242 & 236 & 155 \\
\hline Growth rate & & & & & -50 & 0 & 300 & 200 & 75 & 33.33 & 46.43 & 109.76 & 37.21 & 21.19 & 32.17 & 28.04 & -2.48 & -34.32 \\
\hline Hong Kong & & & 1 & 1 & & 1 & 1 & 1 & 3 & 18 & 23 & 62 & 124 & 155 & 190 & 223 & 192 & 142 \\
\hline Growth rate & & & & 0 & & & 0 & 0 & 200 & 500 & 27.78 & 169.57 & 100.00 & 25.00 & 22.58 & 17.37 & -13.90 & -26.04 \\
\hline Malaysia & & & & & & & & & & 150 & -94 & 510 & -41 & -75 & -10 & -23 & -180 & 87 \\
\hline Growth rate & & & & & & & & & & & -162.96 & -640.46 & -108.04 & 82.81 & -87.10 & 138.52 & 679.97 & -148.51 \\
\hline Brazil & & & 1 & & 2 & 1 & 3 & 5 & 10 & 18 & 39 & 42 & 61 & 95 & 132 & 158 & 181 & 145 \\
\hline Growth rate & & & & & & & 200 & 66.67 & 100 & 80 & 116.67 & 7.69 & 45.24 & 55.74 & 38.95 & 19.70 & 14.56 & -19.89 \\
\hline Sweden & & 1 & & 1 & & 2 & 2 & 2 & 8 & 12 & 31 & 64 & 114 & 111 & 113 & 130 & 165 & 117 \\
\hline Growth rate & & & -100 & & & & 0 & 0 & 300 & 50 & 158.33 & 106.45 & 78.13 & -2.63 & 1.80 & 15.04 & 26.92 & -29.09 \\
\hline Poland & & & & & & 2 & 2 & 4 & 6 & 15 & 17 & 30 & 53 & 92 & 112 & 173 & 159 & 144 \\
\hline Growth rate & & & & & & & 0 & 100 & 50 & 150 & 13.33 & 76.47 & 76.67 & 73.58 & 21.74 & 54.46 & -8.09 & -9.43 \\
\hline World & 7 & 9 & 21 & 19 & 42 & 58 & 124 & 311 & 756 & 1,293 & 2,800 & 4,907 & 7,277 & 9,211 & 11,248 & 13,593 & 11,371 & 8,702 \\
\hline Growth rate & & 28.57 & 133.33 & -9.52 & 121.05 & 38.10 & 113.79 & 150.81 & 143.09 & 71.03 & 116.55 & 75.25 & 48.30 & 26.58 & 22.11 & 20.85 & -16.35 & -23.47 \\
\hline
\end{tabular}


China from 2006 onward. Indeed, in the stage of Consolidated development, China surpasses Europe (in 2010) and the United States (in 2011), and eventually becomes the major player in the realm of graphene research (Gao et al., 2014), covering nearly all the related areas: theory, synthesis, physical and chemical properties, and applications (Chen, 2013). Also noteworthy is the relative shift in positions between the United States and the EU, although after 2014 Europe seems to have secured second place, most likely reflecting governmental support for graphene research (partly driven by the one billion euros Graphene Flagship Project funded by the European Commission and established in 2013). More than 600 projects in the field of graphene and related materials have been initiated in Europe since 2009, with total investment of some 290 million euros. The annual funding level was 49 million $€ /$ year in 2014 (Ciubotaru and Helman, 2015), and about 340 projects were still underway in 2015 .

We may tentatively affirm, at the point in time when this paper was written, that the annual yield in graphene publications still displays exponential growth. Even though the years 2016 and 2017 were not included in the study, the trend established in 2010 largely continues, with China leading in output, and the EU just ahead of the United States in total number of documents.

\section{World Intellectual Structure of Graphene Research (1988-2015)}

Figure A of Table 2 displays the knowledge structure underlying graphene research for the period 1988-2015. At the world level, the network contains 22,802 circles or nodes, gathered in the 51,730 documents retrieved from Scopus database.

The network that represents the knowledge structure is a compact one. It has 359,953 links and a density of 0.01385 . We were surprised by the uniform size of the clusters. The decline in the number of keywords from the first cluster to the last is steady and almost stepwise. This may have to do with the fractional counting used in the calculation of keyword co-occurrences, which could have played a favorable role in this aspect of analysis.

Given the characteristics of scientograms and the methodology behind their construction, when analyzing the knowledge structure, the number of documents contained in a map is indicative of the attention that a domain pays to graphene research, and the number of keywords within each cluster reflects the degree of diversity or specialization. Table 3 shows the equivalence between the number of each cluster and its color. It also gives the 10 keywords appearing most frequently, and the total number contained in each cluster.

In the light of previous experience involving keyword frequency and links (Zulueta et al., 2011; Cantos-Mateos et al., 2012, 2014; Muñoz-Écija et al., 2017), we tagged each cluster, obtaining what would be the seven lines of research that support the knowledge structure of graphene research worldwide: Fundamental Research, Functionalization and Biomedical Applications, Technology and Devices, Materials Science, Energy Storage, Optics, and Chemical Properties and Sensors. According to the clustering algorithm used, the order of the clusters or research lines is determined by their number of keywords. The greater the number of keywords, the higher their position in the hierarchy. If we transfer this structure to other domains, we see that the order changes, thus making manifest which lines of research attract more attention in one domain or another. A comparative look at the scientograms and descriptors of the Complete period and of the Consolidated development period, show them to be practically the same. Again, $94.8 \%$ of the world's graphene research took place within the latter time period, and this goes for all the domains.

Regarding the cluster order, it is worth mentioning that clusters 1, 3, and 4 are related to traditional, general fields linked

TABLE 2 | World intellectual structure of graphene research and its evolution.

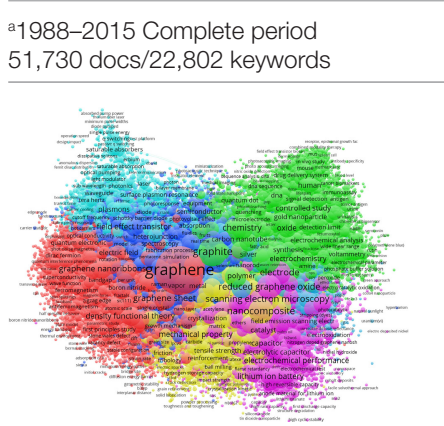

b1988-2003 Preliminary development 110 docs/77 keywords

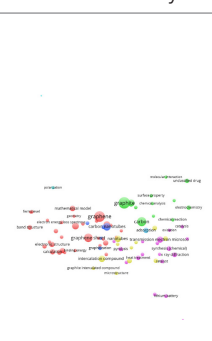

2004-2009 Fast development 2,584 docs/2,117 keywords

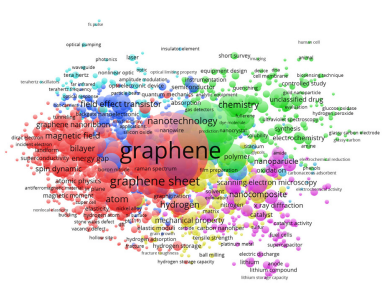

d2010-2015 Consolidated development 49,036 docs/22,036 keywords

${ }^{a}$ Available in high resolution at: http://www.ugr.es/local/benjamin/frontiers/figure2A.png. Available online map and network at: http://www.vosviewer.com/vosviewer.php?map=http:// www.ugr.es/local/benjamin/frontiers/graphene-m.txt\&label_size_variation=0.3\&zoom_level=1\&scale=0.9\&network=http://www.ugr.es/local/benjamin/frontiers/graphene-n.txt\&n_ lines $=10000$.

${ }^{b}$ Available in high resolution at: http://www.ugr.es/local/benjamin/frontiers/figure2B.png. Available online map and network at: http://www.vosviewer.com/vosviewer.php?map=http:// www.ugr.es/local/benjamin/frontiers/w-overlay-88-03.txt\&/abel_size_variation=0.3\&zoom_level=1\&scale=0.9\&network=http://www.ugr.es/local/benjamin/frontiers/w-88-03-n. txt\&n_lines $=100$.

${ }^{\circ}$ Available in high resolution at: $h$ ttp://www.ugr.es/local/benjamin/frontiers/figure2C.png. Available online map and network at: http://www.vosviewer.com/vosviewer.php?map=http:// www.ugr.es/local/benjamin/frontiers/w-overlay-04-09.txt\&/abel_size_variation=0.3\&zoom_level=1\&scale=0.9\&network=http://www.ugr.es/local/benjamin/frontiers/w-04-09-n. txt\&n_lines $=1000$.

${ }^{d}$ Available in high resolution at: http://www.ugr.es/local/benjamin/frontiers/figure2D.png. Available online map and network at: http://www.vosviewer.com/vosviewer.php?map=http:// www.ugr.es/local/benjamin/frontiers/w-overlay-10-15.txt\&/abel_size_variation=0.3\&zoom_level=1\&scale=0.9\&network=http://www.ugr.es/local/benjamin/frontiers/w-10-15-n. txt\&n_lines $=10000$. 
TABLE 3 | Research lines of graphene and descriptors.

\begin{tabular}{|c|c|c|c|c|c|c|c|c|c|c|c|c|c|}
\hline \multicolumn{2}{|l|}{ Cluster 1: red } & \multicolumn{2}{|c|}{ Cluster 2: green } & \multicolumn{2}{|c|}{ Cluster 3: dark blue } & \multicolumn{2}{|c|}{ Cluster 4: yellow } & \multicolumn{2}{|c|}{ Cluster 5: pink } & \multicolumn{2}{|c|}{ Cluster 6: bright turquoise } & \multicolumn{2}{|c|}{ Cluster 7: pacific blue } \\
\hline $\begin{array}{l}\text { Fundamental } \\
\text { research }\end{array}$ & Score & $\begin{array}{l}\text { Functionalization } \\
\text { and biomedical } \\
\text { applications }\end{array}$ & Score & $\begin{array}{l}\text { Technology and } \\
\text { devices }\end{array}$ & Score & Materials Science & Score & Energy storage & Score & Optics & Score & $\begin{array}{l}\text { Chemical } \\
\text { properties and } \\
\text { sensors }\end{array}$ & Score \\
\hline Graphene & 44,983 & Graphite & 7,820 & Carbon nanotubes & 2,523 & Nanocomposite & 4,786 & $\begin{array}{l}\text { Reduced graphene } \\
\text { oxide }\end{array}$ & 4,160 & Plasmons & 867 & Adsorption & 2,366 \\
\hline Graphene sheet & 2,991 & Graphene oxide & 6,979 & $\begin{array}{l}\text { Chemical vapor } \\
\text { deposition }\end{array}$ & 2,342 & $\begin{array}{l}\text { Scanning electron } \\
\text { microscopy }\end{array}$ & 3,796 & $\begin{array}{l}\text { Transmission } \\
\text { electron microscopy }\end{array}$ & 3,941 & Optical property & 746 & Silver & 961 \\
\hline Nanostructure & 2,817 & Chemistry & 3,403 & Raman spectroscopy & 1,974 & Electric conductivity & 1,867 & Electrode & 3,897 & $\begin{array}{l}\text { Optoelectronic } \\
\text { device }\end{array}$ & 471 & Photocatalysis & 925 \\
\hline $\begin{array}{l}\text { Graphene } \\
\text { nanoribbons }\end{array}$ & 2,218 & Carbón & 3,076 & $\begin{array}{l}\text { Atomic force } \\
\text { microscopy }\end{array}$ & 1,907 & Mechanical property & 1,734 & Nanoparticle & 3,787 & Photons & 443 & Titanium dioxide & 920 \\
\hline $\begin{array}{l}\text { Density functional } \\
\text { theory }\end{array}$ & 1,998 & Priority journal & 1,875 & Nanotechnology & 1,852 & Functionalized & 1,558 & X-ray diffraction & 3,262 & Saturable absorbers & 429 & Temperature & 850 \\
\hline Graphene layer & 1,756 & Nanomaterial & 1,734 & Field effect transistor & 1,599 & Electrical conductivity & 1,510 & $\begin{array}{l}\text { X-ray photoelectron } \\
\text { spectroscopy }\end{array}$ & 2,521 & $\begin{array}{l}\text { Surface plasmon } \\
\text { resonance }\end{array}$ & 400 & $\begin{array}{l}\text { Photocatalytic } \\
\text { activity }\end{array}$ & 671 \\
\hline Monolayer & 1,755 & Oxide & 1,640 & Substrate & 1,432 & Polymer & 1,396 & Nanosheet & 2,069 & Light absorption & 366 & $\begin{array}{l}\text { Aromatic } \\
\text { compound }\end{array}$ & 631 \\
\hline Nanoribbons & 1,683 & Surface property & 1,621 & Silicon carbide & 1,290 & Dispersion & 1,369 & Lithium ion battery & 1,668 & Photoluminescence & 365 & Light & 614 \\
\hline Electronic property & 1,680 & Unclassified drug & 1,417 & Room temperature & 1,223 & $\begin{array}{l}\text { Fourier transform } \\
\text { infrared spectroscopy }\end{array}$ & 1,337 & Synthesis (chemical) & 1,627 & Absorption & 353 & Photocatalyst & 545 \\
\hline Molecular dynamic & 1,627 & $\begin{array}{l}\text { Nanostructured } \\
\text { material }\end{array}$ & 1,317 & Electric property & 1,133 & Composite material & 1,304 & $\begin{array}{l}\text { Electrochemical } \\
\text { performance }\end{array}$ & 1,580 & Tera hertz & 338 & Irradiation & 510 \\
\hline Total of keywords & 5,715 & Total of keywords & 4,181 & Total of keywords & 4,060 & Total of keywords & 3,096 & Total of keywords & 2,519 & Total of keywords & 1,772 & Total of keywc & 1,459 \\
\hline
\end{tabular}


with fundamental physical and chemical properties, but also with manufacturing procedures that may be applied to emerging materials, as is the case of graphene. In contrast, the second cluster corresponds to a much more applied field, related to keywords reflecting the application of graphene in the biomedical field. Clusters 5-7 are relatively specific fields, particularly number 6 (Energy Storage) which has been identified by the scientific community as a priority challenge for future technological development (Raccichini et al., 2015).

\section{Evolution of Graphene Research in the World}

Given the temporal division of output into three separate stages, the knowledge structure of graphene can be studied from an evolutionary standpoint.

Figure B in Table 2 represents Preliminary development (1988-2003), according to the overlay map of that period. Use of the link to visualize the graphics in high resolution-whether the overlay map or the online version of VOSviewer-lends the viewer the advantage of grasping the trend of each stage separately, with no need to focus on details.

The scientogram of this period comprises 110 documents, represented by 77 keywords in the overlay map. As seen in Table 4, out of the seven research lines identified in the basemap of the general knowledge structure, in this period "only" the first five are detected: Fundamental Research with 32, Functionalization and Biomedical Applications with 12, Technology and Devices with 5, Materials Science with 11, and Energy Storage with 17 keywords. We emphasize "only" because in the period of Preliminary development, five of the seven lines of research were detected, but just with minimal representation. Obviously, the size of the circles or notes in this period is much smaller than the others, since they are proportional to the number of times each keyword appears in each period.

As depicted in Figure C of Table 2, the Fast development period (2004-2009) reflects a structure conforming just $9.2 \%$ $(2,104$ descriptors) of the knowledge structure of the full period of study, but we find certain indications of the organization that is soon to come. The circles or notes of this scientogram are larger than those of the previous period-see, for instance, graphene (red) or graphite (green). This tells us that the number of documents containing these keywords is proportionally greater than the rest of the documents. At a glance, researchers reveal their topics of interest and the dedication to specific aspects of graphene, evidenced by repeated use of the same keywords. The colors direct us to the same inferences: the greater the number of keywords of a certain color, the more research underway along that line. Furthermore, the greater the degree of overlap or blending of colors, the greater the sharing of knowledge among the respective research lines.

Let us recall that the proximity of keywords is a sign of linkage or interrelation. The keywords of this period, as opposed to the previous one, are similar if we look at the first three positions in the top two research areas: Fundamental Research (red) and Functionalization and Biomedical Applications (green). Lines 3-5-Technology and Devices (blue), Materials Science (yellow), and Energy Storage (pink) - coincide in just one keyword. The last two, Optics (bright turquoise) and Chemical Properties (pacific blue), are of recent appearance on the scene. They did not exist in the period before this one, and, respectively, consist of 87 and 59 keywords. The fact that an ample group of keywords integrate them suggests that their structure is stable. Yet information from the following period shows this to be otherwise. It may well be that during this intermediate stage, works related to optical and chemical properties were included in cluster 1 (Fundamental Research), or even in cluster 2 (Functionalization and Biomedical Applications), the latter especially tied to Chemical Properties and Sensors. Later, during the Consolidated development period, these works were split from clusters 1 and 2 , gaining the critical mass necessary to constitute stable clusters of their own.

Finally, and most importantly, Figure D of Table 2 outlines the knowledge structure of graphene research during the period of Consolidated development (2010-2015). Actually, its distribution tells the tale of the knowledge structure of graphene structure overall, for the whole period of study. It contains $96.84 \%$ $(22,035)$ of all the keywords of reference for the entire 27 -year period. As we saw in the preceding scientogram, the size of the circles indicates concrete aspects under the magnifying glass of researchers, the colors indicate research lines, and overlapping means interaction.

Here we see that the (red) circle of graphene is smaller in this period than in one the immediately before it, because the proportional output is lower; yet it is larger than in the general scientogram for the exact opposite reason. The research lines of this period are better defined, and they practically coincide with the picture of the complete study period. Likewise, overlap indicates that this period marks the true advances in graphene research. The beginning of the stage coincides with the concession of the Nobel Prize to Andre Geim and Konstantin Novoselov for their great achievement of physically isolating graphene. A quick comparison of the keywords within the different research lines of this period, with respect to the previous one, shows that contents in Fundamental Research, Functionalization and Biomedical Applications, Technology and Devices, and Materials Science are similar in the two. Yet there is a remarkable difference in the order of their keywords, that is, the frequency of appearance. Within each separate line of research distinctive priorities can be deduced/spotted. The inference is that these lines have become consolidated in the meantime. The lines Energy Storage (pink), Optical (bright turquoise), and Chemical Properties (pacific blue) have evolved substantially in size and contents, and have only one keyword in common with the previous stage in the cases of Energy Storage and Optics, whereas two are shared in the case of Chemical Properties and Sensors. Such observations can be interpreted as cornerstones of scientific evolution and development within these lines.

It is clear that the interest of graphene as an applied material is overwhelmingly fostered in this period, particularly for biomedical applications, materials science, and the energy storage field. In turn, the Fundamental Research directed toward understanding its properties and the technology involving fabrication procedures has stabilized. 
TABLE 4 | Longitudinal study of the research lines and most frequent keywords in the world.

\begin{tabular}{|c|c|c|c|c|c|c|c|c|c|c|c|c|c|}
\hline \multirow{2}{*}{$\begin{array}{l}\text { Cluster 1: red } \\
\text { Fundamental } \\
\text { research }\end{array}$} & \multirow[b]{2}{*}{ Score } & \multicolumn{2}{|c|}{ Cluster 2: green } & \multicolumn{2}{|c|}{ Cluster 3: dark blue } & \multicolumn{2}{|l|}{ Cluster 4: yellow } & \multicolumn{2}{|c|}{ Cluster 5: pink } & \multicolumn{2}{|c|}{$\begin{array}{l}\text { Cluster 6: } \\
\text { bright turquoise }\end{array}$} & \multicolumn{2}{|c|}{$\begin{array}{l}\text { Cluster 7: } \\
\text { pacific blue }\end{array}$} \\
\hline & & $\begin{array}{l}\text { Functionalization } \\
\text { and biomedical } \\
\text { applications }\end{array}$ & Score & $\begin{array}{l}\text { Technology and } \\
\text { devices }\end{array}$ & Score & $\begin{array}{l}\text { Materials Science } \\
\text { Preliminary } \\
\text { development }\end{array}$ & Score & Energy storage & Score & Optics & Score & $\begin{array}{l}\text { Chemical } \\
\text { properties and } \\
\text { sensors }\end{array}$ & Score \\
\hline Graphene & 40 & Graphite & 47 & Carbon nanotubes & 22 & Intercalation compound & 15 & $\begin{array}{l}\text { Transmission } \\
\text { electron microscopy }\end{array}$ & 14 & & & & \\
\hline Graphene sheet & 27 & Carbon & 31 & Raman spectroscopy & 7 & Nanotubes & 15 & Synthesis (chemical) & 8 & & & & \\
\hline Graphene layer & 17 & $\begin{array}{l}\text { Nanostructured } \\
\text { material }\end{array}$ & 19 & $\begin{array}{l}\text { Chemical vapor } \\
\text { deposition }\end{array}$ & 6 & Carbon fiber & 9 & X-ray diffraction & 8 & & & & \\
\hline Fullerenes & 15 & Electrochemistry & 7 & Graphitization & 6 & Nanofiber & 8 & Heat treatment & 7 & & & & \\
\hline Mathematical model & 12 & Unclassified drug & 7 & Carbon film & 4 & $\begin{array}{l}\text { Scanning electron } \\
\text { microscopy }\end{array}$ & 8 & Pyrolysis & 7 & & & & \\
\hline Total of keywords & 32 & Total of keywords & 12 & Total of keywords & 5 & $\begin{array}{l}\text { Total of keywords Fast } \\
\text { development }\end{array}$ & 11 & Total of keywords & 17 & & & & \\
\hline Graphene & 2,152 & Graphite & 1,233 & Carbon nanotubes & 422 & Electric conductivity & 147 & $\begin{array}{l}\text { Transmission } \\
\text { electron microscopy }\end{array}$ & 135 & Optical property & 47 & Adsorption & 140 \\
\hline Graphene sheet & 412 & Carbon & 321 & Nanotechnology & 198 & Nanotubes & 130 & Nanoparticle & 88 & Absorption & 33 & Crystal structure & 41 \\
\hline Graphene layer & 279 & $\begin{array}{l}\text { Nanostructured } \\
\text { material }\end{array}$ & 182 & Silicon carbide & 152 & Nanocomposite & 110 & Oxygen & 85 & Polarization & 25 & $\begin{array}{l}\text { Semiconductor } \\
\text { material }\end{array}$ & 31 \\
\hline Nanostructure & 244 & Chemistry & 169 & Field effect transistor & 145 & $\begin{array}{l}\text { Scanning electron } \\
\text { microscopy }\end{array}$ & 81 & Synthesis (chemical) & 76 & $\begin{array}{l}\text { Microscopic } \\
\text { examination }\end{array}$ & 24 & Temperature & 29 \\
\hline $\begin{array}{l}\text { Graphene } \\
\text { nanoribbons }\end{array}$ & 230 & Surface property & 129 & Raman spectroscopy & 141 & Functionalized & 78 & Electrode & 65 & Diffraction & 22 & $\begin{array}{l}\text { Aromatic } \\
\text { compound }\end{array}$ & 28 \\
\hline Total of keywords & 925 & Total of keywords & 209 & Total of keywords & 409 & $\begin{array}{l}\text { Total of keywords } \\
\text { Consolidate } \\
\text { development }\end{array}$ & 222 & Total of keywords & 193 & $\begin{array}{l}\text { Total of } \\
\text { keywords }\end{array}$ & 87 & $\begin{array}{l}\text { Total of } \\
\text { keywords }\end{array}$ & 59 \\
\hline Graphene & 43,195 & Graphene oxide & 6,970 & $\begin{array}{l}\text { Chemical vapor } \\
\text { deposition }\end{array}$ & 2,284 & Nanocomposite & 4,686 & $\begin{array}{l}\text { Reduced graphene } \\
\text { oxide }\end{array}$ & 4,162 & Plasmons & 852 & Adsorption & 2,254 \\
\hline Graphene sheet & 2,654 & Graphite & 6,750 & Carbon nanotubes & 2,220 & $\begin{array}{l}\text { Scanning electron } \\
\text { microscopy }\end{array}$ & 3,734 & $\begin{array}{l}\text { Transmission } \\
\text { electron microscopy }\end{array}$ & 3,850 & Optical property & 703 & Silver & 951 \\
\hline Nanostructure & 2,618 & Chemistry & 3,260 & Raman spectroscopy & 1,853 & Electric conductivity & 1,754 & Electrode & 3,840 & $\begin{array}{l}\text { Optoelectronic } \\
\text { device }\end{array}$ & 454 & Photocatalysis & 922 \\
\hline $\begin{array}{l}\text { Graphene } \\
\text { nanoribbons }\end{array}$ & 2,005 & Carbon & 2,864 & $\begin{array}{l}\text { Atomic force } \\
\text { microscopy }\end{array}$ & 1,816 & Mechanical property & 1,668 & Nanoparticle & 3,709 & Photons & 429 & Titanium dioxide & 911 \\
\hline $\begin{array}{l}\text { Density functional } \\
\text { theory }\end{array}$ & 1,843 & Priority journal & 1,746 & Nanotechnology & 1,694 & Functionalized & 1,481 & X-ray diffraction & 3,226 & $\begin{array}{l}\text { Saturable } \\
\text { absorbers }\end{array}$ & 425 & Temperature & 828 \\
\hline Total of keywords & 7,421 & Total of keywords & 4,043 & Total of keywords & 3,109 & Total of keywords & 1,529 & Total of keywords & 1,336 & Total of keywords & 1,305 & $\begin{array}{l}\text { Total of } \\
\text { keywords }\end{array}$ & 1,284 \\
\hline
\end{tabular}




\section{Intellectual Structure of Graphene Research in the United States, Europe and China, and Its Evolution}

Approaching this objective called for designing a table for each geographic domain, in order to show the evolution of the scientograms from one period to the next, as well as the main lines of research reflected by the most-used keywords and the total number of each: Tables 5-7. We also generated a compact visualization of density maps (Table 8) as a way to describe and sum up the evolution of each domain at a quick glance, which further facilitates comparison. In this sense, the density maps can be used as a fast visualization tool to identify the clustering of the main keywords. As examples, in the Consolidated development period, one can easily see that a relatively broad term like "graphene oxide" (a graphene counterpart with growing interest) is closer to keywords related to energy storage (capacitor, electrochemical performance, and lithium) and to biomedical applications (biosensing technique, gold nanoparticle, DNA, etc.) than to keywords related to fundamental research. In contrast, the keyword "field effect transistor" (which may be attributed to a broadly applied field) is closely related with keywords pointing to fundamental research: hot carriers, cutoff frequency, transport problem, etc. Under the scope of the experts in the subject, one can see for instance what kind of production techniques are dominating the technology (chemical vapor deposition), or what physical characterization techniques are the most applied when dealing with the energy storage applications (transmission electron microscopy and X-ray diffraction).

Again, all the maps are available online in high resolution, and can be visualized using the online version of VOSviewer, by simply clicking on the option "Density visualization."

\section{United States}

The United States is found to contribute 20.87\% toward world output in graphene research as far as the number of documents is concerned, and $33.31 \%$ in terms of diversity, in view of the number of keywords, over the complete study period (Table 5).

Analysis of the full time period reveals that the United States investigates and divulges results along all the research lines, though the greatest yield corresponds to Fundamental Research and Technology and Devices. Somewhat behind lie Functionalization and Biomedical Applications. The other lines follow the world trend or the European pattern, in that Preliminary development is scarcely productive. It entails four basic areas: Fundamental Research, Functionalization and Biomedical Applications, Technology and Devices, and Materials Science. Within Fundamental Research, one can clearly discern a subset of keywords associated with the development of tools for the numerical simulation of graphene (electrical density of state, calculation, etc.). The Fast development stage covers all the lines, but especially the first and third mentioned above. The Consolidated development period comes to reaffirm and root the new lines emerging in the period just before.

In this Consolidated period, the keywords related to the Materials Science cluster evoke the structural and electrical characterization intrinsic to Fundamental Research (cluster 1) in the field of Materials Science. China and Europe are the main actors on this stage, and can therefore be considered the driving forces behind the clusters that grow since the Fast development period (Table 8).

\section{Europe}

Europe contributes $18.75 \%$ to world output in graphene research. This figure is slightly less (2.12\%) than the United States harvest and $19.16 \%$ less than China's contribution of scientific documents. The number of keywords points to a research diversity amounting to $28.74 \%$ of the full yield for the period of study (Table 6).

Europe exhibits a behavior similar to that of the United States. In the period of study overall, the focus is seen to be on Fundamental Research and Technology and Devices, and to a lesser extent, on Functionalization and Biomedical Applications. Like that of the United States, Europe's Preliminary development stems from basic research, though it is more productive than the United States in Energy Storage. In the period of Fast development it is active in all research lines, like the United States. However, the number of keywords per research line is lower in all cases, thereby indicating greater specialization or lesser diversity in general. The period of Consolidated development confirms this trend, and all the lines lightly traced before are now established in bold.

Europe could be considered the cradle of graphene. Its laboratories and universities harbored the earliest and most fundamental research, but science is a phenomenon of ramification, sooner or later. Unlike China (though similarly to the United States), Europe invested much effort in developing production/elaboration techniques for the raw material, introducing synthesis, and manufacturing procedures (Bhuyan et al., 2016) (see cluster 3, Technology and Devices). Once the production had been controlled, during the Fast and Consolidated developmental periods, efforts could be devoted to more applied subject areas (mainly clusters 2, 4, 5, and 7).

\section{China}

China's contribution comes to $37.91 \%$ of the worldwide output in graphene research documents, and they represent $33.30 \%$ of the field's diversity, according to the number of keywords (Table 7).

Its scientogram bears a strong resemblance to the world picture, as well as the maps of the United States and EU; but a closer look at the lines of research tells a slightly different story. Over the entire study period, the line Functionalization and Biomedical Applications attracts much more attention (diversity of keywords) in China than in the United States and the EU. Yet in two prioritary research lines in other domains, Fundamental Research and Technology and Devices, China works with the same intensity as the United States and the EU. Deserving mention here are the high number and diversity of keywords found in conjunction with China and Energy Storage. To a somewhat lesser degree, the same is true of Optics and Chemical Properties and Sensors, far better developed in China than in the west.

In general, research within the Preliminary development period is very basic, and hardly existent in China. But this trend was fully overturned between 1999, when its yearly output in graphene documents finally surpassed value 1 , and 2006, when production took flight. It is the only country (albeit with a single 
TABLE 5 | Intellectual structure of graphene research and its evolution in the United States.

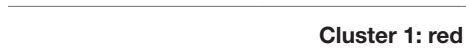

Cluster 1: red Cluster 2: green

\section{Cluster 3: dark blue}

Cluster 4: yellow

Cluster 5: pink

Cluster 6: brigh

turquoise

Cluster 7: pacific

blue

\begin{tabular}{|c|c|c|c|c|c|c|c|c|c|c|c|c|}
\hline $\begin{array}{l}\text { Fundamental } \\
\text { research }\end{array}$ & Score & $\begin{array}{l}\text { Functionalization } \\
\text { and biomedical } \\
\text { applications }\end{array}$ & Score & $\begin{array}{l}\text { Technology } \\
\text { and devices }\end{array}$ & Score & Materials Science & Score & Energy storage & Score & Optics & Score & $\begin{array}{l}\text { Chemical } \\
\text { properties } \\
\text { and sensors }\end{array}$ \\
\hline
\end{tabular}

Complete period

a1988-2015 10,795

docs/7,595 keywords

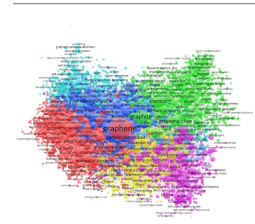

Graphene $\quad 9,810$ Graphite 2,168 Carbon nanotubes

974 Nanotechnolog

748 Nanocomposite

594 Electrode

719 Electric conductivity $483 \quad$ Nanoparticle

624 Plasmons

288 Adsorption 366

Graphene sheet 696 Graphene oxide 845 Chemical vapor

deposition

669 Scanning electron

465 Transmission

545 Optical property

58 Temperature 202

Graphene

654 Carbon

787 Field effect transistor

microscopy

microscopy

533 Optoelectronic

143 Silver

132

anoribbons

649 Functionalized

358 Reduced graphene

device

Molecular dynamic 550 Nanomaterial $\quad 559$ Raman spectroscopy

466 Mechanical property

oxide

135 Crystal structure

Total of keywords $\quad 2,076$ Total of keywords $\quad 1,162$ Total of keywords $\quad 1,770$ Total of keywords 895 Total of keywords

X-ray photoelectron
spectroscopy

332 Tera hertz

130 Light

811 Total of keywords 573 Total of keywords

\section{b1988-2003 29}

docs/15 keywords

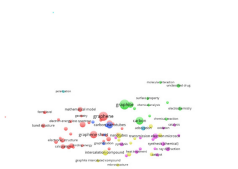

Graphene

Preliminary

development

\begin{tabular}{|c|c|c|c|c|c|c|}
\hline Graphene & 11 & Graphite & 15 & Carbon nanotubes & 8 & Carbon fiber \\
\hline Fullerenes & 7 & Carbon & 12 & & & Nanofiber \\
\hline Graphene sheet & 7 & $\begin{array}{l}\text { Nanostructured } \\
\text { material }\end{array}$ & 8 & & & ubes \\
\hline
\end{tabular}

Calculation

Total of keywords

'2004-2009 1,037

docs/857 keywords

\begin{tabular}{lccccccccccccccc} 
Graphene & 789 & Graphite & 491 & Carbon nanotubes & 137 & Electric conductivity & 61 & $\begin{array}{l}\text { Transmission electron } \\
\text { microscopy }\end{array}$ & 39 & Optical property & 13 & Adsorption & 36 \\
\hline Graphene sheet & 153 & Carbon & 123 & Nanotechnology & 94 & Nanocomposite & 42 & Oxygen & 36 & Plasmons & 9 & Aromatic & 10
\end{tabular}

\begin{tabular}{lllll}
\hline Nanostructure & 91 & Chemistry & 79 & Field effect transistor
\end{tabular}

81 Crystallization

40 Nanoparticle

26 Ultra-fast

compound

Graphene layer

89 Priority journal

74 Silicon carbide

72 Mechanical property

39 Oxidation

59 Nanotubes

71 Room temperature

198 Total of keywords

$39 \quad \mathrm{X}$-ray photoelectron spectroscopy

24 Absorption

nanoribbons

89 Nanostructured

90 Total of keywords

86 Total of keywords

23 Electron optic membrane

Total of keywords

362 Total of keywords

61 Total of keywords property property 
TABLE 5 | Continued

\begin{tabular}{|c|c|c|c|c|c|c|}
\hline Cluster 1: red & Cluster 2: green & Cluster 3: dark blue & Cluster 4: yellow & Cluster 5: pink & $\begin{array}{l}\text { Cluster 6: bright } \\
\text { turquoise }\end{array}$ & $\begin{array}{l}\text { Cluster 7: pacific } \\
\text { blue }\end{array}$ \\
\hline
\end{tabular}

\begin{tabular}{|c|c|c|c|c|c|c|c|c|c|c|c|c|c|}
\hline $\begin{array}{l}\text { Fundamental } \\
\text { research }\end{array}$ & Score & $\begin{array}{l}\text { Functionalization } \\
\text { and biomedical } \\
\text { applications }\end{array}$ & Score & $\begin{array}{l}\text { Technology } \\
\text { and devices }\end{array}$ & Score & Materials Science & Score & Energy storage & Score & Optics & Score & $\begin{array}{l}\text { Chemical } \\
\text { properties } \\
\text { and sensors }\end{array}$ & Score \\
\hline
\end{tabular}

\begin{tabular}{|c|c|c|c|c|c|c|c|c|c|c|c|c|c|c|}
\hline \multirow{2}{*}{$\begin{array}{l}\text { d2010-2015 9,729 } \\
\text { docs } / 7,037 \text { keywords }\end{array}$} & \multicolumn{14}{|c|}{ Consolidate development } \\
\hline & Graphene & 9,009 & Graphite & 1,661 & $\begin{array}{l}\text { Chemical vapor } \\
\text { deposition }\end{array}$ & 644 & Nanocomposite & 552 & Electrode & 600 & Plasmons & 279 & Adsorption & 328 \\
\hline & Nanostructure & 684 & Chemistry & 895 & Nanotechnology & 625 & $\begin{array}{l}\text { Scanning electron } \\
\text { microscopy }\end{array}$ & 434 & Nanoparticle & 519 & Optical property & 144 & Temperature & 186 \\
\hline 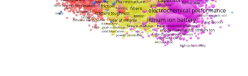 & $\begin{array}{l}\text { Graphene } \\
\text { nanoribbons }\end{array}$ & 565 & Graphene oxide & 827 & Carbon nanotubes & 603 & Electric conductivity & 421 & $\begin{array}{l}\text { Transmission electron } \\
\text { microscopy }\end{array}$ & 491 & $\begin{array}{l}\text { Optoelectronic } \\
\text { device }\end{array}$ & 137 & Silver & 127 \\
\hline & Graphene sheet & 536 & Carbon & 652 & Field effect transistor & 568 & Functionalized & 327 & $\begin{array}{l}\text { Reduced graphene } \\
\text { oxide }\end{array}$ & 408 & Photons & 129 & $\begin{array}{l}\text { Crystal } \\
\text { structure }\end{array}$ & 105 \\
\hline & Molecular dynamic & 498 & Nanomaterial & 502 & Raman spectroscopy & 413 & Thermal conductivity & 321 & $\begin{array}{l}\text { X-ray photoelectron } \\
\text { spectroscopy }\end{array}$ & 309 & Tera hertz & 125 & $\begin{array}{l}\text { Titanium } \\
\text { dioxide }\end{array}$ & 103 \\
\hline & Total of keywords & 1,827 & Total of keywords & 1,123 & Total of keywords & 1,647 & Total of keywords & 835 & Total of keywords & 782 & Total of keywords & 545 & $\begin{array}{l}\text { Total of } \\
\text { keywords }\end{array}$ & 277 \\
\hline
\end{tabular}

aAvailable in high resolution at: http://www.ugr.es/local/benjamin/frontiers/figure5A.png. Available online map and network at: http://www.vosviewer.com/vosviewer.php?map=http://www.ugr.es/local/benjamin/frontiers/u-overlay-88-15. txt\&label_size_variation=0.3\&zoom_level=1\&scale=0.9\&network=http://www.ugr.es/local/benjamin/frontiers/u-88-15-n.txt\&n_lines=10000.

${ }^{b}$ Available in high resolution at: http://www.ugr.es/local/benjamin/frontiers/figure2B.png. Available online map and network at: http://www.vosviewer.com/vosviewer.php?map=http://www.ugr.es/local/benjamin/frontiers/uoverlay-88-03.txt\&label_size_variation=0.3\&zoom_level=1\&scale=0.9\&network=http://www.ugr.es/local/benjamin/frontiers/u-88-03-n.txt\&n_lines=100.

cAvailable in high resolution at: http://www.ugr.es/local/benjamin/frontiers/figure2C.png. Available online map and network at: http://www.vosviewer.com/vosviewer.php?map=http://www.ugr.es/local/benjamin/frontiers/uoverlay-04-09.txt\&label_size_variation=0.3\&zoom_level=1\&scale=0.9\&network=http://www.ugr.es/local/benjamin/frontiers/u-04-09-n.txt\&n_lines=1000.

${ }^{d}$ Available in high resolution at: http://www.ugr.es/local/benjamin/frontiers/figure2D.png. Available online map and network at: http://www.vosviewer.com/vosviewer.php?map=http://www.ugr.es/local//benjamin/frontiers/uoverlay-10-15.txt\&label_size_variation=0.3\&zoom_level=1\&scale=0.9\&network=http://www.ugr.es/local/benjamin/frontiers/u-10-15-n.txt\&n_lines=10000. 
TABLE 6 | Intellectual structure of graphene research and its evolution in Europe (EU).

Cluster 1: red Cluster 2: green

\section{Cluster 3: dark blue}

\section{Cluster 4: yellow}

Cluster 5: pink

Cluster 6: bright

turquoise

Cluster 7:

pacific Blue

Fundamental Score Functionalization Score Technology Score Materials Science Score Energy storage Score Optics Score Chemical Score

applications

properties

and sensors

a1988-2015 9,700

docs $/ 6,553$ keywords

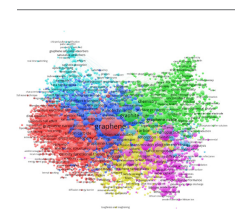

Graphene $\quad$ 8,834 Graphite $\quad 1,733$ Carbon nanotubes

\section{Complete period}

591 Nanocomposite

536 Transmission electron 535 Plasmons microscopy

262 Adsorptio

336

Nanostructure $\quad 580$ Graphene oxide $\quad 743$ Silicon carbide

548 Scanning electron

391 Nanoparticle

443 Optical property

168 Temperature

Graphene layer

548 Carbon

677 Chemical vapor

503 Dispersion

319 Electrode

deposition

Graphene sheet 540 Chemistry

659 Raman spectroscopy 463 Electric conductivity

318 Reduced graphene

390 Photons

123 Silver

Monolayer 494 Nanomateria

369 Nanotechnology

446 Functionalized oxide

Total of keywords 2,142 Total of keywords 919 Total of keywords 1,334 Total of keywords

303 X-ray photoelectron spectroscopy

384 Saturable absorbers

103

83 Total of keywords

5 Surface plasmon

87 Crystal structure

Preliminary

development

b1988-2003 40

docs/20 keywords

Graphene

20 Graphite

22 Carbon nanotubes

6 Intercalation compoun

7 Transmission electron microscopy

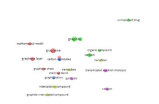

Graphene layer 9 Carbon

11 Graphitization

4 Graphite intercalated

4 Catalyst

4

\begin{tabular}{llll}
\hline Fullerenes & 5 Nanostructured & 9 & Nanofiber
\end{tabular}

4 Pyrolysis

\begin{tabular}{ll} 
& material \\
\hline Mathematical & 5 Organic compound
\end{tabular}

model

Chemical bond

4 Unclassified drug

4

Nanotubes

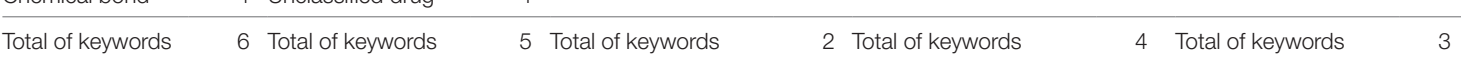

'2004-2009 729

docs/660 keywords

\section{Fast developmen}

Graphene $\quad 664$ Graphite $\quad 375$ Carbon nanotubes 119 Electric conductivity

40 Transmission electron

38 Optical property

15 Adsorption

45

Graphene sheet 110 Carbon

96 Silicon carbide

66 Nanotubes

38 Oxygen

27 Microscopic

10 Crystal structure 17

Graphene layer 99 Chemistry

48 Nanotechnology

50 Crystallization

23 Synthesis (chemical)

25 Polarization

10 Aromatic compound

Nanostructure

64 Nanostructured

46 Semiconducting

40 Nanocomposite

22 Doping (additives)

23 Absorption

8 Semiconductor material 
TABLE 6 | Continued

\begin{tabular}{|c|c|c|c|c|c|c|c|c|c|c|c|c|c|}
\hline \multicolumn{2}{|c|}{ Cluster 1: red } & \multicolumn{2}{|c|}{ Cluster 2: green } & \multicolumn{2}{|c|}{ Cluster 3: dark blue } & \multicolumn{2}{|l|}{ Cluster 4: yellow } & \multicolumn{2}{|l|}{ Cluster 5: pink } & \multicolumn{2}{|c|}{$\begin{array}{l}\text { Cluster 6: bright } \\
\text { turquoise }\end{array}$} & \multicolumn{2}{|c|}{$\begin{array}{l}\text { Cluster 7: } \\
\text { pacific Blue }\end{array}$} \\
\hline $\begin{array}{l}\text { Fundamental } \\
\text { research }\end{array}$ & Score & $\begin{array}{l}\text { Functionalization } \\
\text { and biomedical } \\
\text { applications }\end{array}$ & Score & $\begin{array}{l}\text { Technology } \\
\text { and devices }\end{array}$ & Score & Materials Science & Score & Energy storage & Score & Optics & Score & $\begin{array}{l}\text { Chemical } \\
\text { properties } \\
\text { and sensors }\end{array}$ & Score \\
\hline $\begin{array}{l}\text { Electronic } \\
\text { structure }\end{array}$ & 62 & Surface property & 36 & Raman spectroscopy & 38 & $\begin{array}{l}\text { Scanning electron } \\
\text { microscopy }\end{array}$ & 22 & Nanoparticle & 22 & $\begin{array}{l}\text { Absorption } \\
\text { spectroscopy }\end{array}$ & 8 & Temperature & 8 \\
\hline Total of keywords & 324 & Total of keywords & 71 & Total of keywords & 131 & Total of keywords & 52 & Total of keywords & 47 & Total of keywords & 21 & Total of keywords & 14 \\
\hline
\end{tabular}

d2010-2015 8,931

Consolidate development

docs $/ 6,039$ keywords

\begin{tabular}{|c|c|c|c|c|c|c|c|c|c|c|c|c|c|c|}
\hline \multirow{6}{*}{ 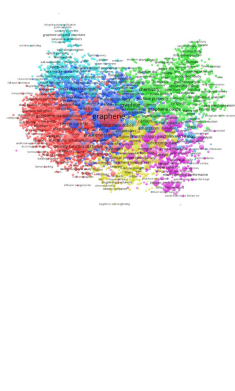 } & Graphene & 8,060 & Graphite & 1,323 & $\begin{array}{l}\text { Chemical vapor } \\
\text { deposition }\end{array}$ & 482 & Nanocomposite & 511 & $\begin{array}{l}\text { Transmission electron } \\
\text { microscopy }\end{array}$ & 487 & Plasmons & 257 & Adsorption & 287 \\
\hline & Nanostructure & 514 & Graphene oxide & 735 & Silicon carbide & 476 & $\begin{array}{l}\text { Scanning electron } \\
\text { microscopy }\end{array}$ & 365 & Nanoparticle & 419 & Optical property & 151 & Temperature & 168 \\
\hline & Graphene layer & 432 & Chemistry & 605 & Carbon nanotubes & 455 & Dispersion & 299 & $\begin{array}{l}\text { Reduced graphene } \\
\text { oxide }\end{array}$ & 384 & Photons & 115 & Silver & 101 \\
\hline & Monolayer & 430 & Carbon & 570 & Raman spectroscopy & 421 & Functionalized & 278 & Electrode & 374 & Saturable absorbers & 93 & Irradiation & 94 \\
\hline & $\begin{array}{l}\text { Density functional } \\
\text { theory }\end{array}$ & 427 & Nanomaterial & 338 & Nanotechnology & 395 & Electric conductivity & 276 & $\begin{array}{l}\text { X-ray photoelectron } \\
\text { spectroscopy }\end{array}$ & 351 & $\begin{array}{l}\text { Surface plasmon } \\
\text { resonance }\end{array}$ & 87 & Titanium dioxide & 91 \\
\hline & Total of keywords & 1,888 & Total of keywords & 889 & Total of keywords & 1,225 & Total of keywords & 742 & Total of keywords & 581 & Total of keywords & 488 & Total of keywords & 226 \\
\hline
\end{tabular}

${ }^{a}$ Available in high resolution at: http://www.ugr.es/local/benjamin/frontiers/figure6A.png. Available online map and network at: http://www.vosviewer.com/vosviewer.php?map=http://www.ugr.es/local//benjamin/frontiers/e-overlay-88-15. txt\&label_size_variation=0.3\&zoom_level=1\&scale=0.9\&network=http://www.ugr.es/local/benjamin/frontiers/e-88-15-n.txt\&n_lines=10000.

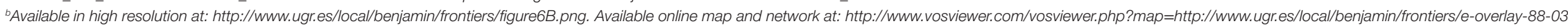
txt\&label_size_variation=0.3\&zoom_level=1\&scale=0.9\&network=http://www.ugr.es/local//benjamin/frontiers/e-88-03-n.txt\&n_lines=100.

'Available in high resolution at: http://www.ugr.es/local/benjamin/frontiers/figure6C.png. Available online map and network at: http://www.vosviewer.com/vosviewer.php?map=http://www.ugr.es/local/benjamin/frontiers/e-overlay-04-09. txt\&label_size_variation=0.3\&zoom_level=1\&scale=0.9\&network=http://www.ugr.es/local/benjamin/frontiers/e-04-09-n.txt\&n_lines=1000.

${ }^{d}$ Available in high resolution at: http://www.ugr.es/local/benjamin/frontiers/figure6D.png. Available online map and network at: http://www.vosviewer.com/vosviewer.php?map=http://www.ugr.es/local/benjamin/frontiers/e

overlay-10-15.txt\&label_size_variation=0.3\&zoom_level=1\&scale=0.9\&network=http://www.ugr.es/local/benjamin/frontiers/e-10-15-n.txt\&n_lines=10000. 
TABLE 7 | Intellectual structure of graphene research and its evolution in China.

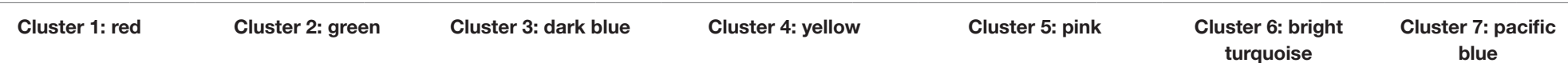

Fundamental Score Functionalization Score Technology Score Materials Science Score Energy storage Score Optics Score Chemical Score

properties applications and sensors

a1988-2015 10,795

docs $/ 7,595$ keywords

\section{Complete period}

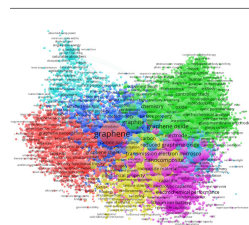

Graphene 16,973 Graphene oxide 3,582 Atomic force

723 Nanocomposite

2,463 Reduced graphene 2,156 Saturable

237 Adsorption 1,157

Graphene sheet 1144 Graphite 2,924 Carbon nanotubes

693 Scanning electron oxide

absorbers

(1,157

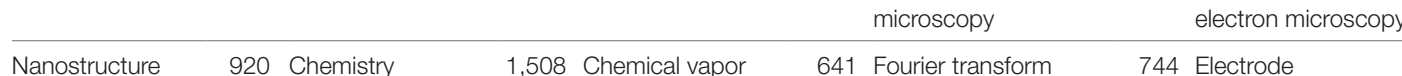

\begin{tabular}{|c|c|c|c|c|c|c|}
\hline Nanostructure & 920 & Chemistry & 1,508 & $\begin{array}{l}\text { Chemical vapor } \\
\text { deposition }\end{array}$ & 641 & $\begin{array}{l}\text { Fourier transform } \\
\text { infrared spectroscopy }\end{array}$ \\
\hline Graphene & 656 & Carbon & 1,179 & Raman & 568 & Mechanical property \\
\hline
\end{tabular}

Graphene
nanoribbons

1,179 Raman

568 Mechanical property

727 Nanoparticle

2,020 Plasmons

233 Photocatalysis 619

Density functional 637 Oxide

spectroscopy

theory

930 Nanotechnology

423 Composite material

711 X-ray diffraction

1,921 Fiber laser

230 Titanium

dioxide

Total of keywords 1,766 Total of keywords $\quad 2,690$ Total of keywords $\quad 1,340$ Total of keywords $\quad$ 1,585 Total of keywords 1,595 Total of keywords

Total of keywords

${ }^{\mathrm{b}} 1988-200329$

docs/15 keywords

Preliminary

development

\begin{tabular}{|c|c|c|c|c|c|c|}
\hline & Graphene sheet & 4 & Carbon nanotubes & 5 & Lithium battery & 4 \\
\hline$=$ & $\begin{array}{l}\text { Single wall } \\
\text { carbon nanotube }\end{array}$ & 4 & & & & \\
\hline - & Total of keywords & 2 & Total of keywords & 1 & Total of keywords & 1 \\
\hline
\end{tabular}

\section{'2004-2009 1,037}

docs/857 keywords

\begin{tabular}{|c|c|c|c|c|c|c|c|c|c|c|c|c|c|c|}
\hline & Graphene & 301 & Graphite & 182 & Carbon nanotubes & 58 & Electric conductivity & 26 & $\begin{array}{l}\text { Transmission } \\
\text { electron microscopy }\end{array}$ & 23 & Absorption & 14 & Adsorption & 28 \\
\hline \multirow{5}{*}{ 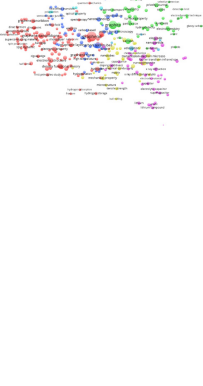 } & $\begin{array}{l}\text { Graphene } \\
\text { nanoribbons }\end{array}$ & 57 & Carbon & 44 & Nanotechnology & 22 & Nanocomposite & 25 & Nanoparticle & 16 & Optical property & 9 & $\begin{array}{l}\text { Aromatic } \\
\text { compound }\end{array}$ & 6 \\
\hline & Graphene sheet & 56 & $\begin{array}{l}\text { Nanostructured } \\
\text { material }\end{array}$ & 28 & $\begin{array}{l}\text { Raman } \\
\text { spectroscopy }\end{array}$ & 20 & Functionalized & 20 & Electrode & 15 & $\begin{array}{l}\text { Optoelectronic } \\
\text { device }\end{array}$ & 6 & Solution & 4 \\
\hline & $\begin{array}{l}\text { Density functional } \\
\text { theory }\end{array}$ & 35 & Chemistry & 25 & $\begin{array}{l}\text { Atomic force } \\
\text { microscopy }\end{array}$ & 18 & $\begin{array}{l}\text { Scanning electron } \\
\text { microscopy }\end{array}$ & 19 & Nanosheet & 15 & Reflection & 6 & Temperature & 4 \\
\hline & $\begin{array}{l}\text { Electronic } \\
\text { structure }\end{array}$ & 31 & Surface property & 21 & Room temperature & 16 & Mechanical property & 17 & Synthesis (chemical) & 15 & Light absorption & 5 & Titanium & 4 \\
\hline & Total of keywords & 128 & Total of keywords & 60 & Total of keywords & 52 & Total of keywords & 43 & Total of keywords & 47 & Total of keywords & 9 & $\begin{array}{l}\text { Total of } \\
\text { keywords }\end{array}$ & 5 \\
\hline
\end{tabular}


TABLE 7 | Continued

$\begin{array}{llllll}\text { Cluster 1: red } & \text { Cluster 2: green } \quad \text { Cluster 3: dark blue } & \text { Cluster 4: yellow } & \text { Cluster 5: pink } & \begin{array}{c}\text { Cluster 6: bright } \\ \text { turquoise }\end{array} & \begin{array}{c}\text { Cluster 7: pacific } \\ \text { blue }\end{array}\end{array}$

\begin{tabular}{|c|c|c|c|c|c|c|c|c|c|c|c|c|c|}
\hline $\begin{array}{l}\text { Fundamental } \\
\text { research }\end{array}$ & Score & $\begin{array}{l}\text { Functionalization } \\
\text { and biomedical }\end{array}$ & Score & $\begin{array}{l}\text { Technology } \\
\text { and devices }\end{array}$ & Score & Materials Science & Score & Energy storage & Score & Optics & Score & Chemical & Score \\
\hline
\end{tabular}
applications

and sensors

\section{d2010-2015 9,729}

docs $/ 7,037$ keywords

\begin{tabular}{|c|c|c|c|c|c|c|c|c|c|c|c|c|c|c|}
\hline & Graphene & 16,671 & Graphene oxide & 3,571 & $\begin{array}{l}\text { Atomic force } \\
\text { microscopy }\end{array}$ & 705 & Nanocomposite & 2,438 & $\begin{array}{l}\text { Reduced graphene } \\
\text { oxide }\end{array}$ & 2,156 & $\begin{array}{l}\text { Saturable } \\
\text { absorbers }\end{array}$ & 236 & Adsorption & 1,128 \\
\hline & Graphene sheet & 1,084 & Graphite & 2,740 & Carbon nanotubes & 630 & $\begin{array}{l}\text { Scanning electron } \\
\text { microscopy }\end{array}$ & 2,009 & $\begin{array}{l}\text { Transmission } \\
\text { electron microscopy }\end{array}$ & 2,072 & Plasmons & 229 & Photocatalysis & 619 \\
\hline$-1=$ & Nanostructure & 889 & Chemistry & 1,483 & $\begin{array}{l}\text { Chemical vapor } \\
\text { deposition }\end{array}$ & 629 & $\begin{array}{l}\text { Fourier transform } \\
\text { infrared spectroscopy }\end{array}$ & 736 & Electrode & 2,005 & Optical property & 223 & $\begin{array}{l}\text { Titanium } \\
\text { dioxide }\end{array}$ & 505 \\
\hline & $\begin{array}{l}\text { Density functional } \\
\text { theory }\end{array}$ & 602 & Carbon & 1,132 & $\begin{array}{l}\text { Raman } \\
\text { spectroscopy }\end{array}$ & 547 & Mechanical property & 710 & Nanoparticle & 1,905 & Fiber laser & 192 & Silver & 489 \\
\hline & $\begin{array}{l}\text { Graphene } \\
\text { nanoribbons }\end{array}$ & 599 & Oxide & 914 & Nanotechnology & 401 & Composite material & 708 & X-ray diffraction & 1,831 & Fiber & 167 & $\begin{array}{l}\text { Photocatalytic } \\
\text { activity }\end{array}$ & 462 \\
\hline & Total of keywords & 1,677 & Total of keywords & 2,667 & Total of keywords & 1,320 & Total of keywords & 1,563 & Total of keywords & 1,575 & Total of & 704 & $\begin{array}{l}\text { Total of } \\
\text { keywords }\end{array}$ & 876 \\
\hline
\end{tabular}

aAvailable in high resolution at: http://www.ugr.es/local/benjamin/frontiers/figure7A.png. Available online map and network at: http://www.vosviewer.com/vosviewer.php?map=http://www.ugr.es/local/benjamin/frontiers/c-overlay-88-15. txt\&label_size_variation=0.3\&zoom_level=1\&scale=0.9\&network=http://www.ugr.es/local/benjamin/frontiers/c-88-15-n.txt\&n_lines=10000.

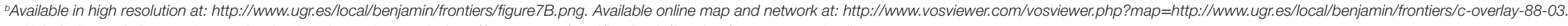
txt\&label_size_variation=0.3\&zoom_level=1\&scale=0.9\&network=http://www.ugr.es/local/benjamin/frontiers/c-88-03-n.txt\&n_lines=100.

cAvailable in high reso/ution at: http://www.ugr.es/local/benjamin/frontiers/figure7C.png. Available online map and network at: http://www.vosviewer.com/vosviewer.php?map=http://www.ugr.es/local/benjamin/frontiers/c-overlay-04-09. txt\&label_size variation=0.3\&zoom_level=1\&scale=0.9\&network=http://www.ugr.es/local/benjamin/frontiers/c-04-09-n.txt\&n_lines=1000.

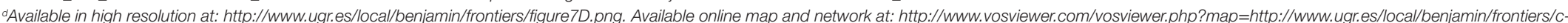

overlay-10-15.txt\&label_size_variation=0.3\&zoom_level=1\&scale=0.9\&network=http://www.ugr.es/local/benjamin/frontiers/c-10-15-n.txt\&n_lines=10000. 
TABLE 8 | Density maps

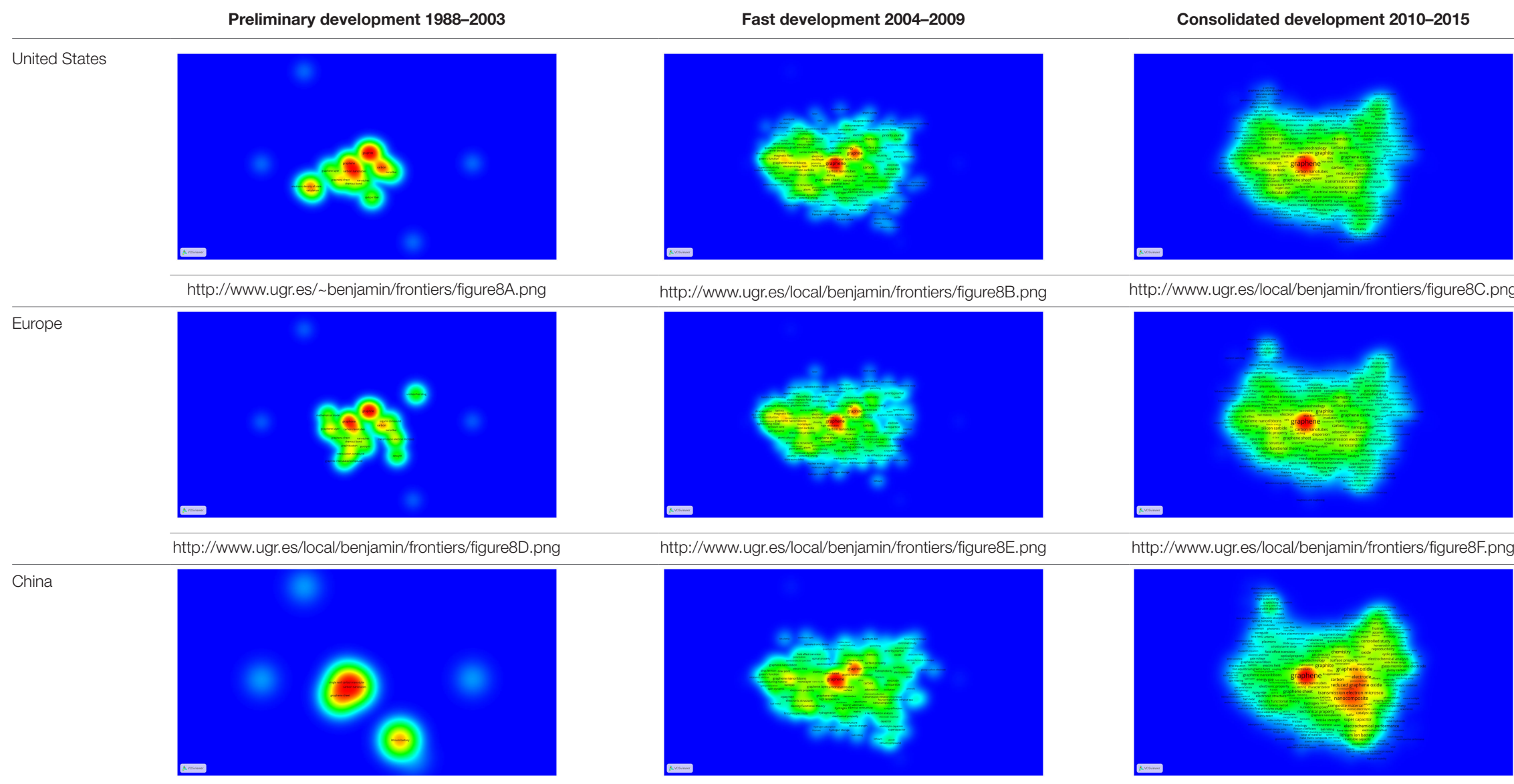

http://www.ugr.es/local/benjamin/frontiers/figure8G.png

http://www.ugr.es/local/benjamin/frontiers/figure8H.png

http://www.ugr.es/local/benjamin/frontiers/figure8l.png 
keyword) that studied Energy Storage from the very onset. China targeted the massive production of batteries as a strategic line for technological development, aiming to become the main supplier of batteries for the emerging electric automotive industry. Thus, any sort of research related to energy storage, or improving the existing technologies by incorporating new materials, such as graphene or reduced graphene oxide, can be seen as a national priority (Ye et al., 2010). The period of Fast development led to exploration of all the new lines diverging from the hub of graphene research, however. Just as in the United States and Europe, China could be characterized by a great diversity of keywords having to do with Functionalization and Biomedical Applications. Consolidated development meant the confirmation of trends initiated in previous years, and the respective map is practically a mirror image of the Complete period.

The drift observed in the current of keywords within the Materials Science cluster in United States and EU (toward Fundamental Research) is not present in China; instead, its keywords are more stable and easily identified, remaining inside the Materials Science field. China has been very prolific in all the areas related to graphene. Although the strongest production takes place during the Consolidated development period, it is clear (Table 8) that much emphasis was placed on Applicationscluster 2: Functionalization and Biomedical Applications; cluster 5: Energy Storage. In particular, China's contribution in cluster 2 is so intense that it would have been very difficult to identify this cluster it if we had only taken into account the contributions of the United States and Europe, separately.

\section{CONCLUSION}

In this work, the intellectual structure of graphene research, its main research lines and its evolution are studied by means of bibliometric and information visualization techniques. Graphene shows a continually growing attraction worldwide, an interest that translates as scientific research and output. In view of the objectives set forth at the beginning of our work, we may affirm that:

1. World output in graphene research began to grow exponentially in 2004, as previously reported (Lv et al., 2011). This growth was spurned by a strong pulse in production in the United States from 2004 onward, and in Europe and China from 2006 onward. Wan and Pan (2010) state that China has placed great vigilance on graphene research, but is out of the way of the driver countries. Five years later, this study shows that China became the undisputed world leader in 2012, largely owing to governmental and financial support from the National Natural Science Foundation of China, the Ministry of Science and Technology of the People's Republic of China, and the Chinese Academy of Sciences (Chen, 2013). A very similar trend was identified in the research field of Nanoscience and Nanotechnology (Chinchilla-Rodríguez et al., 2016). In 2013, it was appraised that 2,200 patents related to graphene were rooted in China (Gao et al., 2014). Europe overtook the United States in graphene output in the year 2014. It is widely recognized that European Research Performing
Organizations contribute very significantly to the overall research objectives associated with graphene, with research and innovation activities that are not directly funded through Collaborative Projects and Coordination and Support Actions (Ciubotaru and Helman, 2015). For example, the Graphene Flagship represents a new form of joint research effort on an unprecedented scale-in fact, Europe's largest research initiative to date-with a budget of one billion euros.

2. We identified the knowledge structure of graphene at the world level, distinguishing seven research lines: Fundamental Research, Functionalization and Biomedical Applications, Technology and Devices, Materials Science, Energy Storage, Optics, Chemical Properties, and Sensors. These findings broadly agree with the areas identified by authors Chen (2013) and Gao et al. (2014). A major part of the worldwide research is found to be concentrated in Energy Storage, Optics, Chemical Properties, and Sensors, pointing to the accentuated interest of Chinese industry in these particular areas. Regarding future trends, we believe that the scientific community will appreciate the clear identification of the clusters of keywords that this work has provided and, especially, the detection of the rise of the "functionalization and biomedical applications," and the "energy storage" clusters as the fields with more promising growth in forthcoming years.

3. Overlay maps are an essential tool for exploring the evolution of graphene research and of any other type of discipline or material. Thanks to them, we gain a personalized and detailed view of the origin, evolution, development, and key factors behind productive efforts at the world level. Still, there must be ways to enhance their utility, and future research should address this challenge.

4. By combining overlay maps with density maps, the advantages become twofold. The sources of research in the United States, $\mathrm{EU}$, and China become visible, and we can see how the evolution in the United States parallels that of Europe in terms of patterns and interests. In China, however, research follows a different path, possibly guided by national economic interests and commercial needs. Despite its comparatively late and timid surge in growth, China clearly dominates the current panorama of applied graphene research for the biomedical field and energy storage, two areas holding vast economic potential.

Although this analysis is founded on currently available tools, a main novelty resides in mapping the disciplinary network structure of the field "graphene research," identifying terms that have a mediating effect in different developmental stages as well as trends in geographical domains. Likewise, the findings can be shared and commented upon among colleagues who see in the online maps what is going on in the research "hot spots," year by year, or in any time period specified.

Despite considerable efforts to represent disciplines and their evolution over time (Klavans and Boyack, 2006), unresolved issues persist on the research platform of bibliometric indicator studies (Leydesdorff and Rafols, 2009). In any case, the findings expounded and illustrated here could help refine research agendas by providing policy makers a better view of the dynamic directions of research. An immediate goal could be to improve the 
baselines for benchmarking exercises, especially those intended to evaluate research endeavors.

\section{LIMITATIONS AND FUTURE RESEARCH}

It is likely that excessive optimism participated in the definition of our objectives in the framework of this study. In the face of the results obtained, the vast dimensions of the factors involved gradually became more apparent. This work served to plant our feet more firmly on the ground amid the numerous methodological pros and cons and the magnitude of the material of study itself.

One consideration that comes up repeatedly in studies of this nature is the database used. Although we relied on Scopus in this case, it would be desirable for future efforts to add/complement data from sources such as WoS, patent databases (USPTO, SP@ CENET, PATENTSCOPE, DWPI, and WIPO Gold), and specialized databases such as Chemical Abstracts Services, along with Web Content Mining techniques (Shapira et al., 2016). It would also be very interesting to replicate this work using other tools such as CiteSpace (Chen, 2004) or SciMAT (Cobo et al., 2012), to see and compare the different perspectives that these tools can bring into view.

Co-word analysis has been improved in the past two decades but still suffers from certain limitations, e.g., the normalization of keywords, indexes applied, counting methods, and the participation of experts (He, 1999; Wang et al., 2012). Here we tried to overcome some of these limitations by normalizing keywords, building a thesaurus, applying fractional counting, and integrating an expert's knowledge in the whole process. Fractional counting proved to be beneficial, possibly because at the network level one can normalize the relative weights of links and thereby clarify the structures within the network (Leydesdorff and Park, 2017), offering highly uniform clusters in size, which reliably reflect what is actually researched, not just the subject matter of the journals where output is presented. At any rate, further analysis should be undertaken to explore alternative techniques so as to refine both methodology and results. For example, overlay maps

\section{REFERENCES}

Aksnes, D. W., Schneider, J. W., and Gunnarsson, M. (2012). Ranking national research systems by citation indicators. A comparative analysis using whole and fractionalised counting methods. J. Inform. 6, 36-43. doi:10.1016/j.joi.2011.08.002

Alcaide-Muñoz, L., Rodríguez-Bolívara, M. P., Cobo, M. J., and Herrera-Viedma, E. (2017). Analysing the scientific evolution of e-Government using a science mapping approach. Gov. Inform. Q. doi:10.1016/j.giq.2017.05.002

Barth, A., and Marx, W. (2008). Graphene: A Rising Star in View of Scientometrics. Available at: https://arxiv.org/ftp/arxiv/papers/0808/0808.3320.pdf

Bhuyan, M., Uddin, M., Islam, M., Bipasha, F., and Hossain, S. (2016). Synthesis of graphene. Int. Nano Lett. 6, 65-83. doi:10.1007/s40089-015-0176-1

Bonaccorsi, A. (2008). Search regimes and the industrial dynamics of science. Minerva 46, 285-315. doi:10.1007/s11024-008-9101-3

Börner, K., Chen, C., and Boyack, K. W. (2003). Visualizing knowledge domains. Annu. Rev. Inform. Sci. 37, 179-255. doi:10.1002/aris.1440370106

Boyack, K. W., Börner, K., and Klavans, R. (2009). Mapping the structure and evolution of chemistry research. Scientometrics 79, 45-60. doi:10.1007/s11192009-0403-5

Boyack, K. W., and Klavans, R. (2014). Creation of a highly detailed, dynamic, global model and map of science. J. Am. Soc. Inf. Sci. Technol. 65, 670-685. doi:10.1002/asi.22990 leave room for improvement, and should be more dynamic. They have inherited the positional structure of the basemap, but their intellectual and internal structure (clusters) are determined by the number of keywords and the associated links, not the basemap.

Knowledge is never static. Its sources and patterns of growth and interaction are constantly shifting and fusing, and output may peak or disappear entirely from view over time. Thus, incorporating new data every year into the basemap in combination with of overlay maps with a series of temporal windows, preferably year by year, or in overlapping periods, would shed more light on the evolution of any type of scientific domain. The easiest way to grasp the structure and evolution of knowledge worldwide is with the help of intuition and visual aids, but adding an element of animation could make bibliometric analyses much more attractive overall.

\section{AUTHOR CONTRIBUTIONS}

BV-Q provided substantial contributions to the conception, design of the work, acquisition, analysis, and interpretation of data for the work. ZC-R worked drafting the work and revising it critically for important intellectual content. NR worked drafting the work and revising it critically for important intellectual content.

\section{ACKNOWLEDGMENTS}

Financial support from the Spanish National Plan for Scientific and Technical Research and Innovation is acknowledged (Research project CSO2014-57770-R).

\section{FUNDING}

Projects I + D + I, State Program of Research, Development, and Innovation oriented to the Challenges of the Society: NANOMETRICS (Ref. CSO2014-57770-R) Supported by Ministerio de Economía y Competitividad of Spain.

Boyack, K. W., Klavans, R., and Börner, K. (2005). Mapping the backbone of science. Scientometrics 64, 351-374. doi:10.1007/s11192-005-0255-6

Boyack, K. W., Newman, D., Duhon, R. J., Klavans, R., Patek, M., Biberstine, J. R., et al. (2011). Clustering more than two million biomedical publications: comparing the accuracies of nine text-based similarity approaches. PLOS ONE 6: e18029. doi:10.1371/journal.pone.0018029

Braam, R. R., Moed, H. F., and van Raan, A. F. J. (1991a). Mapping of science by combined co-citation and word analysis. I. Structural aspects. J. Am. Soc. Inform. Sci. 42, 233-245.doi:10.1002/(SICI)1097-4571(199105)42:4<233:AID-ASI1>3.0.CO;2-I

Braam, R. R., Moed, H. F., and van Raan, A. F. J. (1991b). Mapping of science by combined co-citation and word analysis. II: dynamical aspects. J. Am. Soc. Inform. Sci. 44, 252-266. doi:10.1002/(SICI)1097-4571(199105)42:4<252:AIDASI2>3.0.CO;2-G

Callon, M., Courtial, J., and Laville, F. (1991). Co-word analysis as a tool for describing the network of interactions between basic and technological research: the case of polymer chemistry. Scientometrics 22, 155-205. doi:10.1007/BF02019280

Callon, M., Courtial, J. P., Turner, W. A., and Bauin, S. (1983). From translations to problematic networks: an introduction to co-word analysis. Soc. Sci. Inform. 22, 191-235. doi:10.1177/053901883022002003

Cantos-Mateos, G., Vargas-Quesada, B., Chinchilla-Rodriguez, Z., and Zulueta, M. A. (2012). Stem cell research. Bibliometric analysis of main research areas through keywords plus. Aslib Proc. 64, 561-590. doi:10.1108/00012531211281698 
Cantos-Mateos, G.,Zulueta,M.A., Vargas-Quesada, B., andChinchilla-Rodriguez,Z. (2014). Estudio evolutivo de la investigación española con células madre. Visualización e identificación de las principales líneas de investigación. Prof. Inf. 23, 259-271. doi:10.3145/epi.2014.may.06

Chadegani, A. A., Salehi, H., Yunus, M., Farhadi, H., Fooladi, M., Farhadi, M., et al. (2013). A comparison between two main academic literature collections: web of science and scopus databases. Asian Soc. Sci. 9, 18-26. doi:10.5539/ass. v9n5p18

Chen, C. (2004). Searching for intellectual turning points: progressive knowledge domain visualization. PNAS 101, 5303-5310. doi:10.1073/pnas.0307513100

Chen, C. (2006). CiteSpace II: detecting and visualizing emerging trends and transient patterns in scientific literature. J. Am. Soc. Inf. Sci. Technol. 57, 359-377. doi:10.1002/asi.20317

Chen, C., Paul, R. J., and O'Keefe, B. (2001). Fitting the jigsaw of citation: information visualization in domain analysis. J. Am. Soc. Inf. Sci. 52, 315-330. doi:10.1002/1532-2890(2000)9999:9999<:AID-ASI1074>3.0.CO;2-2

Chen, K. (2013). Graphene research in China. Mater. Res. Soc. Symp. Proc. 1505, 1-4. doi:10.1557/opl.2013.185

Chinchilla-Rodríguez, Z., Ocaña-Rosa, K., and Vargas-Quesada, B. (2016). How to combine research guarantor and collaboration patterns to measure scientific performance of countries in scientific fields: nanoscience and nanotechnology as a case study. Front. Res. Metr. Anal. 1:2. doi:10.3389/frma.2016.00002

Ciubotaru, A. M., and Helman, A. (2015). Graphene-Based Revolutions in ICT and Beyond Combination of CP and CSA. Available at: https://grapheneflagship.eu/Lists/Deliverables/D16.3\%20Report\%20on\%20mapping\%20of\% 20European\%20graphene\%20research.pdf

Cobo, M. J., Chiclana, F., Collop, A., de Oña, J., and Herrera-Viedma, E. (2014). A bibliometric analysis of the intelligent transportation systems research based on science mapping. IEEE. Trans. Intell. Transp. Syst. 15, 901-908. doi:10.1109/ TITS.2013.2284756

Cobo, M. J., López-Herrera, A. G., Herrera, F., and Herrera-Viedma, E. (2012). SciMAT: a new science mapping analysis software tool. J. Assoc. Inf. Sci. Technol. 63, 1609-1630. doi:10.1002/asi.22688

Cobo, M. J., López-Herrera, A. G., Herrera-Viedma, E., and Herrera, F. (2011a). An approach for detecting, quantifying, and visualizing the evolution of a research field: a practical application to the fuzzy sets theory field. J. Inform. 5, 146-166. doi:10.1016/j.joi.2010.10.002

Cobo, M. J., López-Herrera, A. G., Herrera-Viedma, E., and Herrera, F. (2011b). Science mapping software tools: review, analysis and cooperative study among tools. J. Assoc. Inf. Sci. Technol. 62, 1382-1402. doi:10.1002/asi.21525

Cobo, M. J., Martínez, M. A., Gutiérrez-Salcedo, M., Fujita, H., and HerreraViedma, E. (2015). 25 years at knowledge-based systems: a bibliometric analysis. Knowl. Based Syst. 80, 3-13. doi:10.1016/j.knosys.2014.12.035

Collazo-Reyes, F. (2014). Growth of the number of indexed journals of Latin America and the Caribbean: the effect on the impact of each country. Scientometrics 98, 197-209. doi:10.1007/s11192-013-1036-2

Ding, Y., Chowdhury, G. G., and Foo, S. (2001). Bibliometric cartography of information retrieval research by using co-word analysis. Inform. Process. Manag. 37, 817-842. doi:10.1016/S0306-4573(00)00051-0

Gao, H., Liu, Z., and Feng, X. (2014). From 2004 to 2014: a fruitful decade for graphene research in China. Small 10, 2121. doi:10.1002/smll.201400915

Garfield, E. (1986). "Towards scientography," in Essays of an Information Scientist, Vol. 9, 324. Available at: http://www.garfield.library.upenn.edu/essays/ v9p324y1986.pdf

Gómez-Núñez, A. J., Vargas-Quesada, B., Chinchilla-Rodríguez, Z., Batagelj, V., and Moya-Anegón, F. (2016). Visualization and analysis of SCImago Journal \& Country Rank structure via journal clustering. Aslib J. Inf. Manag. 68, 607-627. doi:10.1108/AJIM-12-2015-0205

GrapheneFlagship.(2013).Availableat:https://graphene-flagship.eu/project/Pages/ About-Graphene-Flagship.aspx

He, Q. (1999). Knowledge discovery trhoug co-word analysis. Libr. Trends 48, 133-159.

Klavans, R., and Boyack, K. W. (2006). Quantitative evaluation of large maps of science. Scientometrics 68, 475-479. doi:10.1007/s11192-006-0125-x

Klavans, R., and Boyack, K. W. (2009). Toward a consensus map of science. J. Am. Soc. Inf. Sci. Technol. 60, 455-476. doi:10.1002/asi.20991

Klavans, R., and Boyack, K. W. (2011). Using global mapping to create more accurate document-level maps of research fields. J. Am. Soc. Inf. Sci. Technol. 62, 1-18. doi:10.1002/asi.21444
Klincewicz, K. (2016). The emergent dynamics of a technological research topic: the case of graphene. Scientometrics 106, 319-345. doi:10.1007/s11192-015-1780-6

Leta, J. (2011). "Growth of Brazilian Science: a real internalization or a matter of databases coverage?" in Proceedings of ISSI 2011-The 13th International Conference of the International Society for Scientometrics and Informetrics, Vol. 1 (Durban, Africa do Sul), 392-397.

Leydesdorff, L. (1989). The relations between qualitative theory and scientometric methods in science and technology studies. Scientometrics 15, 333-347. doi:10.1007/BF02017058

Leydesdorff, L. (2007a). Visualization of the citation impact environments of scientific journals: an online mapping exercise. J. Am. Soc. Inf. Sci. Technol. 58, 25-38. doi:10.1002/asi.20406

Leydesdorff, L. (2007b). Mapping interdisciplinarity at the interfaces between the Science Citation Index and the Social Science Citation Index. Scientometrics 71, 391-405. doi:10.1007/s11192-007-1694-z

Leydesdorff, L., and Bornman, L. (2012). Mapping (USPTO) patent data using overlays to Google Maps. J. Am. Soc. Inf. Sci. Technol. 64, 1442-1458. doi:10.1002/asi.22666

Leydesdorff, L., Carley, S., and Rafols, I. (2013a). Global maps of science based on the new Web-of-Science categories. Scientometrics 94, 589-593. doi:10.1007/ s11192-012-0784-8

Leydesdorff, L., Rafols, I., and Chen, C. (2013b). Global maps of science based on the new Web-of-Science categories. J. Assoc. Inf. Sci. Technol. 64, 2573-2586. doi:10.1002/asi.22946

Leydesdorff, L., Moya-Anegón, F., and Guerrero-Bote, V. P. (2010). Journal maps on the basis of Scopus data: a comparison with the journal citation reports of the ISI. J. Am. Soc. Inf. Sci. Technol. 61, 352-369. doi:10.1002/asi.21250

Leydesdorff, L., and Nerghes, A. (2017). Co-word maps and topic modeling: a comparison using small and medium-sized corpora $(\mathrm{N}<1,000)$. J. Assoc. Inf. Sci. Technol. 68, 1024-1035. doi:10.1002/asi.23740

Leydesdorff, L., and Park, H. W. (2017). Full and fractional counting in bibliometric networks. J. Inform. 11, 117-120. doi:10.1016/j.joi.2016.11.007

Leydesdorff, L., and Persson, O. (2010). Mapping the geography of science: distribution patterns and networks of relations among cities and institutes. J. Am. Soc. Inf. Sci. Technol. 61, 1622-1634. doi:10.1002/asi.21347

Leydesdorff, L., and Rafols, I. (2009). A global map of science based on the ISI subject categories. J. Am. Soc. Inf. Sci. Technol. 60, 348-362. doi:10.1002/asi.20967

Leydesdorff, L., and Rafols, I. (2012). Interactive overlays: a new method for generating global journal maps from Web-of-Science data. J. Inform. 6, 318-322. doi:10.1016/j.joi.2011.11.003

Leydesdorff, L., and Schank, T. (2008). Dynamic animations of journal maps: indicators of structural change and interdisciplinary developments. J. Am. Soc. Inf. Sci. Technol. 59, 1810-1818. doi:10.1002/asi.20891

López-Herrera, A. G., Cobo, M. J., Herrera-Viedma, E., and Herrera, F. (2010). A bibliometric study about the research based on hybridating the fuzzy logic field and the other computational intelligent techniques: a visual approach. Int. J. Hybrid Intell. Syst. 17, 17-32. doi:10.3233/HIS-2010-0102

Lv, P. H., Wang, G.-F., Wan, Y., Liu, J., Liu, Q., and Ma, F.-C. (2011). Bibliometric trend analysis on global graphene research. Scientometrics 88, 399-419. doi:10.1007/s11192-011-0386-x

Martínez, M. A., Cobo, M. J., Herrera, M., and Herrera-Viedma, E. (2015). Analyzing the scientific evolution of social work using science mapping. Res. Soc. Work Pract. 25, 257-277. doi:10.1177/1049731514522101

Moral-Muñoz, J. A., Cobo, M. J., Peis, E., Arroyo-Morales, M., and HerreraViedma, E. (2014). Analyzing the research in integrative \& complementary medicine by means of science mapping. Complement. Ther. Med. 22, 409-418. doi:10.1016/j.ctim.2014.02.003

Moya-Anegón,F.,Chinchilla-Rodríguez,Z., Vargas-Quesada,B., Corera-Álvarez,E., Gonzalez-Molina, A., Munoz-Fernandez, F. J., et al. (2007a). Coverage analysis of Scopus: a journal metric approach. Scientometrics 73, 53-78. doi:10.1007/ s11192-007-1681-4

Moya-Anegón,F., Vargas-Quesada,B.,Chinchilla-Rodríguez,Z.,Corera-Álvarez,E., Munoz-Fernández, F. J., and Herrero-Solana, V. (2007b). Visualizing the marrow of science. J. Am. Soc. Inf. Sci. 58, 2167-2179. doi:10.1002/asi.20683

Moya-Anegón,F., Vargas-Quesada,B., Herrero-Solana, V.,Chinchilla-Rodríguez,Z., Corera-Álvarez, E., and Muñoz-Fernández, F. J. (2004). A new technique for building maps of large scientific domains based on the cocitation of classes and categories. Scientometrics 61, 129-145. doi:10.1023/B:SCIE.0000037368. 31217.34 
Muñoz-Écija, T., Vargas-Quesada, B., and Chinchilla-Rodriguez, Z. (2017). Identification and visualization of the intellectual structure and the main research lines in nanoscience and nanotechnology at the worldwide level. J. Nanopart. Res. 19, 1-25. doi:10.1007/s11051-016-3732-3

Munoz-Sandoval, E. (2014). Trends in nanoscience, nanotechnology, and carbon nanotubes: a bibliometric approach. J. Nanopart Res. 16, 1-22. doi:10.1007/ s11051-013-2152-x

Murgado-Armenteros, E. M., Gutiérrez-Salcedo, M., Torres-Ruiz, F. J., and Cobo, M. J.(2015). Analysing the conceptual evolution of qualitative marketing research through science mapping analysis. Scientometrics 102, 519-557. doi:10.1007/s11192-014-1443-z

Novoselov, K. S., Fal'ko, V. I., Colombo, L., Gellert, P. R., Schwab, M. G., and Kim, K. (2012). A roadmap for graphene. Nature 490, 192-200. doi:10.1038/ nature 11458

Novoselov, K. S., Geim, A. K., Morozov, S. V., Jiang, D., Zhang, Y., Dubonos, S. V., et al. (2004). Electric field in atomically thin carbon films. Science 306, 666-669. doi:10.1126/science.1102896

Noyons, E. C., Moed, H. F., and Luwel, M. (1999). Combining mapping and citation analysis for evaluative bibliometric purposes: a bibliometric study. J. Assoc. Inf. Sci. Technol. 50, 115-131. doi:10.1002/(SICI)1097-4571(1999)50: $2<115$ :AID-ASI3 > 3.0.CO;2-J

Odegard, G. M., Gates, T. S., Nicholson, L. M., and Wise, K. E. (2002). Equivalentcontinuum modeling of nano-structured materials. Compos. Sci. Technol. 62, 1869-1880. doi:10.1016/S0266-3538(02)00113-6

Perianes-Rodriguez, A., Waltman, L., and van Eck, N. J. (2016). Constructing bibliometric networks: a comparison between full and fractional counting. J. Inform. 10, 1178-1195. doi:10.1016/j.joi.2016.10.006

Peters, H. P. F., and van Raan, A. F. (1993a). Co-word-based science maps of chemical engineering. Part I: representations by direct multidimensional scaling. Res. Policy 22, 23-45. doi:10.1016/0048-7333(93)90031-C

Peters, H. P. F., and van Raan, A. F. (1993b). Co-word-based science maps of chemical engineering. Part II: representations by combined clustering and multidimensional scaling. Res. Policy 22, 47-71. doi:10.1016/0048-7333(93) 90032-D

Raccichini, I., Varzi, A., Passerini, S., and Scrosati, B. (2015). The role of graphene for electrochemical energy storage. Nat. Mater. 14, 271-279. doi:10.1038/ nmat4170

Rafols, I., Porter, A. L., and Leydesdorff, L. (2010). Science overlay maps: a new tool for research policy and library management. J. Am. Soc. Inf. Sci. Technol. 61, 1871-1887. doi:10.1002/asi.21368

Rodriguez-Ledesma, A., Cobo, M. J., Lopez-Pujalte, C., and Herrera-Viedma, E. (2015). An overview of animal science research 1945-2011 through science mapping analysis. J. Anim. Breed. Genet. 132, 475-497. doi:10.1111/ jbg. 12124

Rotolo, D., Rafols, I., Hopkins, M., and Leydesdorff, L. (2017). Strategic intelligence on emerging technologies: scientometric overlay mapping. J. Assoc. Inf. Sci. Technol. 68, 214-233. doi:10.1002/asi.23631

Shapira, P., Abdullah, G., and Fatemeh, S. (2016). Graphene enterprise: mapping innovation and business development in a strategic emerging technology. J. Nanopart. Res. 18, 1-24. doi:10.1007/s11051-016-3572-1

Shapira, P., Youtie, J., and Carley, S. (2010). Graphene Research Profile: UK and US Publications, 2000-2010. Available at: http://works.bepress.com/cgi/viewcontent.cgi article $=1026 \&$ context $=$ pshapira
Small, H., Boyack, K. W., and Klavans, R. (2014). Identifying emerging topics in science and technology. Res. Policy 43, 1450-1467. doi:10.1016/j.respol. 2014.02.005

Small, H., and Garfield, E. (1985). The geography of science: disciplinary and national mappings. J. Inf. Sci. 11, 147-159.

Soos, S., Kampis, G., and Gulyás, L. (2013). Large-scale temporal analysis of computer and information science. Eur. Phys. J. Spec. Topics 222, 1441-1465. doi:10.1140/epjst/e2013-01936-6

Stock, W. G., and Stock, M. (2013). Handbook of Information Science. Berlin: Gruyter Saur.

Terekhov, A. I. (2015). R \& D on carbon nanostructures in Russia: scientometric analysis, 1990-2011. J. Nanopart. Res. 17, 1-26. doi:10.1007/s11051-015-2897-5

Van Eck, N. J., and Waltman, L. (2010). Software survey: VOSviewer, a computer program for bibliometric mapping. Scientometrics 84, 523-538. doi:10.1007/ s11192-009-0146-3

Van Eck, N. J., and Waltman, L. (2016). VOSviewer Manual: Version 1.6.5. Available at: http://www.vosviewer.com/download/f-y2s2.pdf

Vargas-Quesada, B., and Moya-Anegón, F. (2007). Visualizing the Structure of Science. New York, NY: Springer.

Wallace, P. R. (1947). The band theory of graphite. Phys. Rev. 71, 622-634. doi:10.1103/PhysRev.71.622

Waltman, L., van Eck, N. J., and Noyons, E. (2010). A unified approach to mapping and clustering of bibliometric networks. J. Inform. 4, 629-635. doi:10.1016/ j.joi.2010.07.002

Wan, L., and Pan, Y.-T. (2010). Research frontiers and trends and graphene research. Carbon 49, 1806-1809. doi:10.1016/j.carbon.2010.12.027

Wang, Z. Y., Li, G., Li, C. Y., and Li, A. (2012). Research on the semantic-based co-word analysis. Scientometrics 90, 855-875. doi:10.1007/s11192-011-0563-y

Ye, J., Chen, X., and Zhao, Q. (2010). "Energy supply strategy for battery electric vehicles in China," in International Conference on Optoelectronics and Image Processing (Haiko), 483-487.

Zhang, J., Yu, Q., Zheng, F., Long, C., Lu, Z., and Duan, Z. (2016). Comparing keywords plus of WOS and author keywords: a case study of patient adherence research. J. Am. Soc. Inf. Sci. Technol. 67, 967-972. doi:10.1002/asi.23437

Zulueta, M.-A., Cantos-Mateos, G., Vargas-Quesada, B., and Sánchez, C. (2011). Research involving women and health in the Medline database, 1965-2005: co-term analysis and visualization of main lines of research. Scientometrics 88, 679-706. doi:10.1007/s11192-011-0455-1

Conflict of Interest Statement: The authors declare that the research was conducted in the absence of any commercial or financial relationships that could be construed as a potential conflict of interest.

The reviewer, EY, and handling Editor declared their shared affiliation, and the handling Editor states that the process nevertheless met the standards of a fair and objective review.

Copyright (c) 2017 Vargas-Quesada, Chinchilla-Rodríguez and Rodriguez. This is an open-access article distributed under the terms of the Creative Commons Attribution License (CC BY). The use, distribution or reproduction in other forums is permitted, provided the original author(s) or licensor are credited and that the original publication in this journal is cited, in accordance with accepted academic practice. No use, distribution or reproduction is permitted which does not comply with these terms. 